\title{
EL TURISMO ACCESIBLE EN ANDALUCÍA. UN PRODUCTO TURÍSTICO EMERGENTE $^{1}$
}

\section{ACCESSIBLE TOURISM IN ANDALUSIA. EMERGING TOURISM PRODUCT}

\author{
José Manuel Jurado Almonte \\ Universidad de Huelva \\ jurado@uhu.es
}

Recibido: febrero, 2014.

Versión final aceptada: abril, 2014.

PALABRAS CLAVE: Turismo accesible, accesibilidad universal, discapacidad, Andalucía.

KEYWORDS: Accessible tourism, universal accessibility, disability, Andalusia.

\section{RESUMEN}

A pesar de lo avanzado en la accesibilidad universal y en la integración de personas con alguna discapacidad sensorial o locomotriz, resta mucho por hacer, y especialmente en lo que se refiere al turismo accesible. Un fenómeno creciente y de enormes potencialidades y oportunidades económicas y sociales.

No obstante, surgen novedosas experiencias públicas y privadas de destinos y equipamientos de uso público y vocación turística especialmente volcadas con este amplio y diverso colectivo que son interesantes de resaltar por sus trascendencias empresariales y sociales. Asimismo, se trata de una nueva tipología o modelo, el del turismo accesible, con notables indefiniciones conceptuales y muy poco estudiado desde la geografía. Nuestra atención se va a centrar esta vez en Andalucía, aunque su análisis es inseparable de las escalas de España y Europa.

\section{ABSTRACT}

Despite the progress in universal accessibility and integration of people with sensory or locomotor disability, much remains to be done, especially in regards to accessible tourism. A growing phenomenon of enormous potential and economic and social opportunities.

However, there have been innovative public and private experiences of destinations and facilities for public use and tourist vocation especially focused on this large and

\footnotetext{
${ }^{1}$ Esta aportación es una actualización, con especial atención hacia el ámbito de Andalucía, del artículo JURADO ALMONTE., J.M. (2014): "El turismo accesible en Andalucía y Portugal", en Cuadernos de Turismo, no 33, pp. 121-150, Universidad de Murcia. ISSN 1139-7861. Disponible on line en: http://revistas.um.es/turismo/article/view/195681/160201
}

ISSN: 0212-8594 ISSN-e: 2340-2776.No DOI: http://dx.doi.org/10.12795/rea.2014.i31.01 
diverse group which are interesting to highlight because of their business and social transcendence. Also, it is a new typology or model, accessible tourism, with notable conceptual uncertainties and scantily studied from Geography. Our attention will be focused this time in Andalusia, although its analysis is inseparable from the scales of Spain and Europe. 


\section{INTRODUCCIÓN.}

Este artículo tiene su origen en la investigación "El turismo accesible en Andalucía y Portugal" (2012). La particularidad de elegir Portugal se debió al objetivo transfronterizo del proyecto inicial del que surgió el estudio.

Dicho estudio partió de la hipótesis que el turismo accesible además de su vertiente social, también es una actividad económica que se puede convertir en una oportunidad de formación y trabajo para personas (con y sin discapacidad) que realizan su actividad en el sector turístico (hotelería, hostelería, etc.). Al mismo tiempo, representa una ocasión para que los equipamientos públicos y privados, sujetos a la visita de viajeros y turistas, mejoren y logren una accesibilidad universal, atendiendo precisamente a una legislación, proveniente de diversas escalas, que exige una igualdad e integración social en la prestación de servicios.

Con posterioridad al Estudio (2011-2012) ${ }^{2}$, se hizo un resumen del mismo que fue finalmente publicado en Cuadernos de Turismo (con un material de origen de 2012) ${ }^{3}$. Pero pasado un tiempo desde entonces, se retoma de nuevo esta investigación con dos objetivos principales: la actualización de aspectos legislativos y de algunas experiencias de turismo accesible $y$, en segundo lugar, centrar la atención en la Comunidad Autónoma de Andalucía.

En consecuencia, este estudio, en sus 140 páginas, jalonado también de material gráfico, tuvo el índice de contenido que a continuación se detalla (tabla 1). No obstante, la atención en esta aportación se va a centrar en el marco de la investigación, el concepto de turismo accesible y en comentar algunas experiencias de turismo accesible.

\section{EL TURISMO ACCESIBLE: ESTADO DE LA INVESTIGACIÓN Y FUENTES DE INFORMACIÓN.}

Frente a una extensísima literatura investigadora sobre temas turísticos, principalmente desde los campos de la Geografía y la Economía, hallamos una escasa bibliografía y bagaje estadístico sobre el llamado turismo accesible (T.A.), quizás por la indefinición existente aún de este producto turístico que es muy transversal con otras temáticas.

\footnotetext{
2JURADO ALMONTE, J.M. (2012): Turismo accesible en Andalucía y Portugal. ACTUAN. Redacción de José M. Jurado, 140 pág. ACTUAN. Financiación del Programa Euroempleo, Consejería de Empleo, Junta de Andalucía.

3 JURADO ALMONTE., J.M. (2014): “El turismo accesible en Andalucía y Portugal”, en Cuadernos de Turismo, no 33, pp. 121-150, Universidad de Murcia. ISSN 1139-7861. Disponible on line en: http://revistas.um.es/turismo/article/view/195681/160201
}

ISSN: 0212-8594 ISSN-e: 2340-2776.N№ DOI: http://dx.doi.org/10.12795/rea.2014.i31.01 
Tabla 1. Esquema de contenido del Estudio "El turismo accesible en Andalucía y Portugal" (2012)".
1. Introducción
2. El turismo accesible. Conceptualización.
3. La accesibilidad del turista con discapacidad
4. La accesibilidad integral o universal
5. Legislación y planificación de la accesibilidad y la discapacidad
6. Marco institucional de la accesibilidad y la discapacidad.
7. Municipio y accesibilidad
8. Concienciación, formación y empleo en cuanto a la accesibilidad y la discapacidad
9. La población con discapacidad en España, Andalucía y Portugal
10. Experiencias en turismo accesible en Andalucía y Portugal
11. Diagnóstico
12. Propuestas
13. Conclusiones y últimas reflexiones
14. Bibliografía y fuentes documentales

Por tanto, encarar el estudio de "El Turismo Accesible en Andalucía y Portugal", resultó todo un reto investigador. Particularmente, ha supuesto el descubrimiento de nuevos organismos generadores de información turística $y$, sobre todo, de tipo social; la comprensión de novedosos marcos legislativos; ratificarme en la enorme interdisciplinariedad y transversalidad de este tipo de investigaciones, independientemente de la procedencia académica de sus investigadores; la importancia de este tema como objeto de investigación; la necesidad y el derecho del turismo accesible para amplias capas sociales; y las enormes oportunidades económicas, formativas y de empleo que tienen nuestro sector turístico y nuestros territorios ibéricos de potenciarse la accesibilidad turística.

El término "Turismo accesible" (o "Turismo para todos") es relativamente reciente. Fue utilizado por primera vez en el Informe Baker publicado en el Reino Unido en 1989, y hace referencia a la cuestión de la accesibilidad a través de la supresión de barreras urbanísticas y arquitectónicas así como a la integración social a través del turismo de las personas con algún tipo de discapacidad. Sin duda, abordar el turismo accesible debe hacerse también contando con la Accesibilidad y la discapacidad o dependencia. Por tanto, entran en juego conocimientos y experiencias de otros campos del saber: arquitectura, urbanismo, sociología, economía, etc. No basta sólo con consultar trabajos e investigadores de la geografía, sino muchas otras investigaciones, de autoría particular o institucional. Precisamente, y es lo que se quiero recalcar en este primer epígrafe, encontramos mayor profusión bibliográfica en la investigación de esta temática entre otras disciplinas y ciencias que en Geografía.

Repasando la bibliografía de Geografía, para el caso de España, sólo se ha hallado un interesante trabajo realizado por geógrafos que analizan específicamente esta temática. Me refiero a Mónica Molina Hoyo y Gema Cánoves Valiente (2010), de la 
Universidad Autónoma de Barcelona, publicado en el no 25 de la Revista "Cuadernos de Turismo", y en el que abordan la situación del turismo accesible en Cataluña y España.

Algo más numerosos son los trabajos procedentes de la rama de Económicas. En este sentido, una interesante aportación es la de María Teresa Fernández Alles, de la Facultad de Ciencias Económicas y Empresariales de la Universidad de Cádiz, quien después de defender su Tesis Doctoral titulada "Turismo accesible: análisis de la accesibilidad hotelera en la provincia de Cádiz" (2007) ha publicado diversos artículos en revistas del campo de la economía. En uno de sus artículos (2009), la autora, además de destacar la relevancia del tema, hace hincapié en la bibliografía en España en materia de accesibilidad turística. Concluye que "en España, la investigación en materia de accesibilidad turística ha sido escasa hasta hace pocos años y que queda mucho camino por recorrer (pág. 150).

Muy parecido por su temática y por la bibliografía y fuentes utilizadas es el trabajo de Tesis Doctoral de Trinidad Domínguez (2009): "Marketing turístico para personas con discapacidad. El producto turístico accesible", de la Facultad de Ciencias Empresariales y Turismo de Vigo, quien realiza otros diversos artículos sobre esta temática firmados también por Fraiz, J.A. y Alén, Mạ L. (2011).

Estas tres fuentes referenciadas se asemejan por ser muy recientes en el tiempo, con publicaciones de hace escasos años, lo que es muestra de lo reciente que es esta línea de investigación, y porque utilizan unas mismas fuentes documentales, legislativas y estadísticas. De esta manera, pocas diferencias hay por la temática y bibliografía, independientemente de la procedencia académica de estas investigadoras. Es ilustrativo, pues, que no hallamos en estas autoras ninguna referencia bibliográfica a significativos geógrafos españoles de la Geografía del Turismo.

Con mayor antelación cronológica a los anteriores autores, y que suelen ser muy citados, destacan los trabajos en inglés de Brown F. (1991), Burnett, J.J. (1996 y 2001), Darcy, S. (1998); Brinckmann, W. E. y Wildgen, J. S. (2003), Centi, S. y otros (2004); Buhalis, D. y otros (2005) o en francés: Furnion, L. (2001).

No obstante, las investigaciones -en español- más referenciadas proceden del ámbito de la arquitectura y el urbanismo: Grünewald, L.A. (1996), Franco, P. (1995 y 1999), Godoy, A., (1999), Sanchiz Pons, N. (1998 y 2000). Alonso López, F. (1999 y 2002), Marcos Pérez, D. (2002), Marcos Pérez, D. y González Velasco, D. (2003), Sala Mozos y Alonso López, F. (2006) y Alonso, F. y Dinarès, M. (2006). También encontramos interesantes aportaciones desde el campo de la sociología turística: Rubio, Ángeles (2000), Delgado, J.I. (2004), Huesca, A. y Ortega, E. (2005), Soret Lafraya, P. (2005) y Sánchez, M. J.; Santiago, G., y Soret, P. (2007).

ISSN: 0212-8594 ISSN-e: 2340-2776.N№ DOI: http://dx.doi.org/10.12795/rea.2014.i31.01

REA 31 (2014):1-34

http://www.publius.us.es/estudios_andaluces 
Igualmente destacan las aportaciones de diversos organismos públicos que en sus páginas webs podemos encontrar ingente información sobre legislación, guías, monografías y estudios, en muchos casos desplegables, realizados por diferentes autores y consultoras especializados sobre cuestiones técnicas de discapacidad $^{4}$ y accesibilidad turística.

En este sentido, a escala internacional sobresale la Organización Mundial de Personas con Discapacidad y la Organización Internacional de Turismo Social. Para el ámbito más concreto de la Unión Europea destaca el Foro Europeo de la Discapacidad (EDF) y, recientemente, en 2006, se creó la Red ENAT (Europan Network for Accesible Tourism - Red Europea de Turismo Accesible) $)^{5}$.

Para el caso de España sobresalen (tabla 2): el Instituto de Mayores y Asuntos Sociales (IMSERSO) el Centro Estatal de Autonomía, Personas y Ayudas Técnicas (CEAPAT), el Observatorio Estatal de la Discapacidad (OED), el Real Patronato sobre Discapacidad (RPD), el Servicio de Información sobre Discapacidad (SID), el Centro Español de Documentación sobre Discapacidad (CEDD) y el Centro Nacional de Tecnologías de la Accesibilidad (CENTAC).

A su vez, la llamada sociedad civil tiene un notable protagonismo a través de numerosísimas federaciones, fundaciones y asociaciones, ramificadas desde la escala estatal a la regional y provincial, que realizan actividades de protección y promoción de las personas discapacitadas, mayores o consumidores y que luchan a favor de la mejora de la accesibilidad universal. Todas ellas cuentan con potentes webs, muy interrelacionadas, y en las que podemos obtener una variada información sobre la accesibilidad, la discapacidad y el turismo accesible. Estas asociaciones juegan un papel importante en la defensa de los intereses de las personas con discapacidad. Entre éstas destacan: la Plataforma Representativa Estatal de Discapacitados Físicos (PREDIF), el Comité Español de Representantes de Personas con Discapacidad (CERMI), Confederación Española de Personas con Discapacidad Física y Orgánica (COCEMFE) y la Fundación ONCE.

\footnotetext{
${ }^{4}$ Debemos considerar que el problema de la discapacidad no reside en la propia persona con discapacidad, sino en la existencia de un entorno discapacitante, es decir, en la existencia de barreras arquitectónicas, urbanísticas, en los transportes, en las comunicaciones y, en general, en el acceso a dispositivos técnicos diseñados para un consumidor medio con amplias capacidades y habilidades, lo cual está lejos de la realidad social y demográfica (IMSERSO, 2005).

${ }^{5}$ Con esta Red ENAT se pretende dar una información más precisa sobre la accesibilidad en el turismo. La información que posee su web puede ser muy determinante en lo que se refiere al turismo accesible, con una potencial población con discapacidad de 80 millones de personas en la UE. No obstante, su campo de acción se extiende más allá de la UE. De esta manera, según refleja su web, la red ENAT incluye más de 430 miembro en 52 países y cinco continentes. Ver en: http://www.accessibletourism.org/
}

ISSN: 0212-8594 ISSN-e: 2340-2776.№ DOI: http://dx.doi.org/10.12795/rea.2014.i31.01

REA 31 (2014):1-34

http://www.publius.us.es/estudios_andaluces 
Tabla 2. Algunas instituciones y web en España destacables por su información con respecto a la discapacidad y la accesibilidad.

\begin{tabular}{|l|l|}
\hline Instituciones & Web \\
\hline $\begin{array}{l}\text { - CEAPAT. Centro Estatal de Autonomía Personal y } \\
\text { Ayudas Técnicas }\end{array}$ & www.ceapat.es \\
\hline $\begin{array}{l}\text { - CEDD. Centro Español de Documentación sobre } \\
\text { Discapacidad }\end{array}$ & http://www.cedd.net/es/ \\
\hline $\begin{array}{l}\text { - CENTAC. Centro Nacional de Tecnologías de la } \\
\text { Accesibilidad }\end{array}$ & http://www.centac.es/ \\
\hline $\begin{array}{l}\text { - CERMI. Comité Español de Representantes de Personas } \\
\text { con Discapacidad }\end{array}$ & www.cermi.es \\
\hline - CNSE. Confederación Estatal de Personas Sordas. & www.cnse.es \\
\hline $\begin{array}{l}\text {-COCEMFE. Confederación Coordinadora Estatal de } \\
\text { Personas con Discapacidad Física y Orgánica de España. }\end{array}$ & www.cocemfe.es \\
\hline $\begin{array}{l}\text { - CRID. Centro de Recursos para a Inclusão Digital } \\
\text { - FEAPS. Federación Española de Asociaciones con } \\
\text { discapacidades psíquicas }\end{array}$ & $\begin{array}{l}\text { http://www.crid.esecs.iple } \\
\text { iria.pt/ }\end{array}$ \\
\hline $\begin{array}{l}\text { - FIAPAS. Confederación Española de Padres y Amigos de } \\
\text { los Sordos. }\end{array}$ & http://www.feaps.org/ \\
\hline - IMSERSO. Instituto de Mayores y Servicios Sociales & www.imserso.es \\
\hline $\begin{array}{l}\text { - OED. Observatorio Estatal de la Discapacidad } \\
\text { - ONCE. Organización Nacional de Ciegos de España }\end{array}$ & $\begin{array}{l}\text { http://www.observatoriod } \\
\text { eladiscapacidad.es/ }\end{array}$ \\
\hline - POLIBEA. Turismo sin barreras. Agencia de Viajes. & www.once.es \\
\hline - PORTAl de cidadão com Deficiência & http://www.pcd.pt/ \\
\hline $\begin{array}{l}\text { - PREDIF. Plataforma Representativa Estatal de } \\
\text { Discapacitados Físicos }\end{array}$ & http://www.predif.org/ \\
\hline - REAL Patronato sobre Discapacidad. & www.rpd.es \\
\hline - SID. Servicio de Información sobre Discapacidad & http://sid.usal.es/ \\
\hline
\end{tabular}

Fuente: Elaboración propia (2012).

Esta estructura institucional y asociativa para la escala estatal se repite de alguna manera en cada comunidad autónoma española, las cuales, además, tienen competencias, y es el caso de Andalucía, en materia de accesibilidad, discapacidad, dependencia, formación y políticas turísticas, entre otras. Por otra parte, es necesario recalcar la transversalidad de las políticas de accesibilidad y discapacidad, pudiendo tener protagonismo distintas consejerías, además de las de Asuntos Sociales.

Para el ámbito de Andalucía y en esta temática tan trasversal destacan las Consejerías de Salud y Bienestar Social, Economía, Innovación, Ciencia y Empleo y la de Turismo y Comercio. Esta última consejería ha publicado la obra "Turismo accesible. Dossier" 
$(2008)^{6}$ que recoge un amplio conjunto de referencias bibliográficas, principalmente en español y hasta dicha fecha, de monografías y legislaciones referentes, directa o indirectamente, al turismo accesible y que sirve no sólo para el estudio de este fenómeno en Andalucía, sino también para otros ámbitos territoriales principalmente de España.

Asimismo, la Consejería de Turismo y Comercio ha desarrollado un escenario de reflexión virtual en la red llamado "Microproductos y Segmentos Emergentes", con la intención de que la ciudadanía colabore con "Nuevas ideas" entre los 16 productos o segmentos turísticos emergentes se destaca el de "turismo accesible". Es un interesante documento donde por primera vez al turismo accesible se le da la etiqueta de segmento turístico emergente. En cambio, en la misma Consejería, hay otro documento web en el que aparece información estadística y documental variada de 14 segmentos turísticos ${ }^{8}$ (entendidos como consolidados) entre los que no se halla el turismo accesible. Por último, la empresa pública Turismo Andaluz mantiene abierta una web con importante información y enlaces sobre el turismo, la accesibilidad y la discapacidad ${ }^{9}$.

Como señalábamos, no existen aún estadísticas que recojan específicamente el fenómeno del turismo accesible. En consecuencia, hemos de conformarnos, transversalmente, con las estadísticas sobre población con discapacidad. Para el caso de España, tenemos la Encuesta sobre Discapacidades, Deficiencias y Estado de salud (EDDES-1999) y, más reciente, la Encuesta de Discapacidad, Autonomía personal y situaciones de Dependencia (EDAD-2008), ambas del Instituto Nacional de Estadística y disponibles en su web. A su vez, de ésta última, el Instituto de Estadística y Cartografía de Andalucía (IECA) ha realizado una versión con mayor profusión informativa de esta misma fuente estadística ${ }^{10}$.

También hay que destacar la consulta de diversos documentos de planificación turística en los que están presentes entre sus objetivos el deseo de mejorar la accesibilidad turística. Para el caso de España destacan el Plan Turismo Español Horizonte, $2020^{11}$ y el Plan Nacional e Integral de Turismo (PNIT), 2012-2015 ${ }^{12}$, ambos

\footnotetext{
${ }^{6}$ Consejería de Turismo y Comercio (2008): Turismo y Comercio Turismo accesible. Dossier. Ver en: http://www.juntadeandalucia.es/turismocomercioydeporte/documentacion/31604.pdf

${ }^{7}$ Consejería de Turismo y Comercio (2013): “Microproductos y Segmentos Emergentes", Ver en: http://www.turismonuevasideas.org/foros/microproductos-y-segmentos-emergentes

8 Consejería de Turismo y Comercio (2013): Encuesta a los segmentos turísticos. Ver en: http://www.juntadeandalucia.es/turismoycomercio/opencms/estadisticas/estadisticas-oficiales-de-laconsejeria-de-turismo-comercio-y-deporte/index.html\#encuesta

${ }^{9}$ Turismo Andaluz (2013): Guía de la accesibilidad en comunicación de los alojamientos turísticos. Ver en: http://www.turismoandaluz.com/sites/accesibilidad/discapacidad.html

${ }^{10}$ Ver en: http://www.juntadeandalucia.es/institutodeestadisticaycartografia/dependencia/index.htm

${ }^{11}$ Ver en: http://www.turisme2015bcn.cat/files/7931-56arxiUCAT/PLAN\%20TURISMO\%20ESPA\%C3\%910L\%202020.\%20DOCUMENTO\%20EJECUTIVO.pdf

${ }^{12}$ Ver en : http://www.tourspain.es/es-es/VDE/Paginas/PNIT.aspx
} 
del Ministerio de Industria, Turismo y Comercio, o la Estrategia española sobre Discapacidad 2012-2020 ${ }^{13}$, del Ministerio de Sanidad, Seguridad y Servicios Sociales. Para el caso de Andalucía destacan el Plan General de Turismo Sostenible de Andalucía, $2014-2020^{14}$ y el Plan Director de Promoción Turística de Andalucía, 2013-2016 ${ }^{15}$ de la Consejería de Turismo y Comercio. Y en lo que concierne a las cuestiones sociales, tenemos el II Plan de Acción Integral para las personas con discapacidad en Andalucía $2011-2013^{16}$.

Al margen de estas planificaciones de escalas amplias es importantísimo el papel de los municipios o ayuntamientos. Éstos cuentan o podrían contar en aras a mejorar la accesibilidad integral y obligar el cumplimiento de distintas legislaciones con poderosas herramientas, con fuerza de ley, como son: el Planeamiento urbanístico, las Ordenanzas Municipales, los Planes municipales de movilidad y los diversos Planes Especiales de Accesibilidad.

Finalmente, no se puede comprender todo lo que concierne al turismo accesible, por su enorme transversalidad, sin tener en cuenta el marco legislativo que concierne a la accesibilidad y la discapacidad. Y para ello, este análisis no puede quedarse sólo en Andalucía sino que ha de ampliarse a la escala de España, Unión Europea e, incluso, internacional (es el caso de la ONU) (tabla 3).

Por tanto, sumergirse en el estudio del turismo accesible, independientemente del ámbito territorial y de la rama del conocimiento de procedencia del investigador, conlleva en primer lugar un gran esfuerzo, dada la enorme transversalidad, por conocer todo lo que lleva parejo la accesibilidad y la discapacidad, en sus vertientes sociales, económicas y técnicas. Para ello es imprescindible manejar una bibliografía extensa sobre estos temas, así como estadísticas, legislaciones, normativas y planes estratégicos y de actuación; tener en cuenta la información procedente de numerosas administraciones, asociaciones, fundaciones y empresas que intervienen en esta compleja y transversal temática; y, por último, un imprescindible trabajo de campo para conocer experiencias en turismo accesible.

\section{EL TURISMO ACCESIBLE: CONCEPTUALIZACIÓN Y VENTAJAS.}

Existe un segmento poblacional y social, con capacidad de movimiento y sensorial reducido, pero con unos derechos y unas necesidades de ocio y turismo crecientes y que, por tanto, exigen una mayor atención pública y privada. Además, este segmento

\footnotetext{
${ }^{13}$ Ver en: http://www.msssi.gob.es/ssi/discapacidad/informacion/estrategiaEspanolaDiscapacidad.htm

${ }^{14}$ Ver en: http://issuu.com/tecnicoturismo/docs/plangturismosostenible

${ }^{15}$ Ver en: http://www.andalucia.org/es/profesional/plan-director-de-promocion-turistica-2013-2016/

${ }^{16}$ Ver en:

http://www.juntadeandalucia.es/igualdadybienestarsocial/opencms/system/bodies/Personas_Discapaci dad/Planes/II_PAIPDA/IIPAIPDA20112013v.pdf
}

ISSN: 0212-8594 ISSN-e: 2340-2776.№ DOI: http://dx.doi.org/10.12795/rea.2014.i31.01

REA 31 (2014):1-34

http://www.publius.us.es/estudios_andaluces 
poblacional y, a la vez, potencial demandante turístico va en aumento en las sociedades desarrolladas, como consecuencia del envejecimiento demográfico.

Tabla 3. Principales legislaciones y acuerdos internacionales de tipo social que intervienen en la accesibilidad y la discapacidad en España y Andalucía.

\begin{tabular}{|c|c|}
\hline \multicolumn{2}{|l|}{ Organización de las Naciones Unidades (ONU) } \\
\hline $\begin{array}{l}\text { Resolución 48/96, “Normas Uniformes sobre la Igualdad de } \\
\text { Oportunidades para las personas con Discapacidad" }\end{array}$ & 1993 \\
\hline $\begin{array}{l}\text { Convención 61/106 sobre los "Derechos de las personas con } \\
\text { discapacidad", aprobada el } 13 \text { de diciembre de } 2006\end{array}$ & 2006 \\
\hline \multicolumn{2}{|l|}{ Unión Europea (UE) } \\
\hline $\begin{array}{l}\text { Comunicación de la Comisión sobre Igualdad de Oportunidades de las } \\
\text { personas con Minusvalía }\end{array}$ & 1996 \\
\hline $\begin{array}{l}\text { Directiva 2000/78/CE del Consejo, de } 27 \text { de noviembre de } 2000 \text {, } \\
\text { relativa al establecimiento de un marco general para la igualdad de } \\
\text { trato en el empleo y la ocupación. }\end{array}$ & $\begin{array}{l}\text { Noviembre de } \\
2000\end{array}$ \\
\hline $\begin{array}{l}\text { Comunicación 2000, 284, "Hacia una Europa sin barreras para las } \\
\text { personas con discapacidad" }\end{array}$ & $\begin{array}{l}\text { Diciembre de } \\
2000\end{array}$ \\
\hline $\begin{array}{l}\text { Dictamen sobre "el turismo social en Europa"(2006/C 318/12). Comité } \\
\text { Económico y Social Europeo de la UE }\end{array}$ & $\begin{array}{l}\text { Diciembre de } \\
2006\end{array}$ \\
\hline \multicolumn{2}{|l|}{ Ámbito Estatal de España } \\
\hline $\begin{array}{l}\text { Ley 51/2003 sobre Igualdad de Oportunidades, No-Discriminación y } \\
\text { Accesibilidad Universal (LIONDAU, 2003), reformada en } 2013\end{array}$ & $\begin{array}{l}\text { BOE núm. } 289 \text {, } \\
\text { de } 3 \text { de } \\
\text { diciembre }\end{array}$ \\
\hline $\begin{array}{l}\text { Ley } 39 / 2006 \text {, de } 14 \text { de diciembre, de Promoción de la Autonomía } \\
\text { Personal y Atención a las personas en situación de dependencia, más } \\
\text { conocida como Ley de Dependencia }\end{array}$ & $\begin{array}{l}\text { BOE no 300, } 16 \\
\text { diciembre2006 }\end{array}$ \\
\hline $\begin{array}{l}\text { Ley } 26 / 2011 \text {, de } 1 \text { de agosto, de adaptación normativa a la Convención } \\
\text { Internacional sobre los derechos de personas con discapacidad }\end{array}$ & $\begin{array}{l}\text { (BOE 184 de } \\
\text { 2/8/2011). }\end{array}$ \\
\hline \multicolumn{2}{|l|}{ Ámbito de Andalucía } \\
\hline $\begin{array}{l}\text { Decreto } 72 / 1992 \text {, de } 5 \text { de mayo, establece las normas técnicas para la } \\
\text { accesibilidad y eliminación de barreras arquitectónicas, urbanísticas y } \\
\text { en el transporte en Andalucía }\end{array}$ & $\begin{array}{l}\text { BOJA, de } 23 \text { de } \\
\text { julio de } 1992 .\end{array}$ \\
\hline $\begin{array}{l}\text { Ley } 1 / 1999 \text {, de } 31 \text { de marzo, de Atención a las personas con } \\
\text { discapacidad en Andalucía }\end{array}$ & $\begin{array}{l}\text { BOJA no 45, de } \\
17 \text { de abril de } \\
1999\end{array}$ \\
\hline $\begin{array}{l}\text { Decreto } 293 / 2009 \text {, de } 7 \text { de julio, por el que se aprueba el Reglamento } \\
\text { que regula las normas para la accesibilidad en las infraestructuras, el } \\
\text { urbanismo, la edificación y el transporte en Andalucía }\end{array}$ & $\begin{array}{l}\text { BOJA no 140, } \\
\text { de } 21 \text { de julio } \\
2009\end{array}$ \\
\hline
\end{tabular}

Fuente: Elaboración propia (2012). 
Esta población demanda un entorno urbano y social más integrador donde poder desarrollarse como ciudadanos de pleno derecho. En este sentido, se ha avanzado en la accesibilidad integral o universal, principalmente porque lo fuerzan las leyes y disposiciones, pero no es suficiente. De esta manera, este segmento demográfico no encuentra siempre un viario urbano y una arquitectura adaptada a las distintas discapacidades. Pero no todo es accesibilidad arquitectónica, puesto que este tipo de demanda, a pesar también de algunos avances, tampoco encuentra con frecuencia un servicio y una formación que especialmente contemplen y atiendan sus discapacidades físicas y sensoriales. Así, trabajar en el sector turístico convencional no es lo mismo que hacerlo particularmente para el llamado turismo social y accesible. Las necesidades de este colectivo social y, a su vez, potencial clientela, exigen un plus de formación para los profesionales, que prestan también un servicio turístico a la población sin discapacidades

Una justa forma de inclusión social, además de otras, es también el ocio y el turismo. De esta manera, el tejido empresarial vinculado al turismo es consciente cada vez más de la importancia también económica de este colectivo, además de las obligaciones y recomendaciones de las legislaciones de cara a una plena accesibilidad e integración social.

Especialmente desde los países desarrollados de la Unión Europea, que son también las principales áreas emisoras y receptoras de turistas, se está experimentado en los últimos años un inusitado interés por el segmento poblacional de mayores y personas con discapacidades. No obstante, y a pesar del marco jurídico de la UE, existen diferentes sensibilidades y niveles de desarrollo en cuanto a la accesibilidad. En este sentido, en territorios eminentemente turísticos como España y, dentro de la misma, Andalucía, a pesar de su indudable avance, queda aún muchas cosas que hacer y nichos de mercados turísticos que potenciar, como es el caso del turismo accesible, especialmente pensado para este tipo de demanda.

Los cambios son tan rápidos que, a la vuelta de pocos años, el propio concepto de turismo accesible, entendido como aquel que persigue la supresión de barreras a la accesibilidad, va transformándose en turismo para todos, en un deseo de extender el turismo y la accesibilidad para toda la sociedad, todas las edades, en personas con o sin discapacidad, en todo tipo de contextos vitales (medios de transportes, espacios públicos, áreas residenciales y equipamientos públicos y privados) y que las posibilidades de ocio y turismo lleguen también a grupos sociales menos favorecidos.

Turismo accesible + Turismo social $=$ Turismo para todos

La competencia es casi inherente a la oferta de las empresas y territorios turísticos. Todos intentan vender sus bondades en un mercado muy competitivo, con una demanda turística muy cambiante y exigente y con una globalidad e inmediatez de la información y las reservas turísticas. Ya no vale vender sólo los atractivos naturales y

ISSN: 0212-8594 ISSN-e: 2340-2776.N№ DOI: http://dx.doi.org/10.12795/rea.2014.i31.01

REA 31 (2014):1-34

http://www.publius.us.es/estudios_andaluces 
patrimoniales de un territorio, así como las excelencias en confort de un alojamiento hotelero o de un restaurante, sino también es importante vender el concepto de la accesibilidad integral aplicada, en este caso, al turismo. Entendiéndola en un sentido amplio se refiere no sólo a la eliminación de alguna barrera arquitectónica en un centro de alojamiento y/o de restauración, sino a todo un proceso amplio y variado desde que un turista, con o sin discapacidad, opta por hacer turismo, elije un territorio, un alojamiento, lugares de interés para visitar, recrearse y comer y, después, hacer el viaje de vuelta.

En todas estas circunstancias debe estar inherente el concepto de la accesibilidad integral. En primer lugar, por razones de derechos sociales, para poder alcanzar una vida independiente y de calidad y conseguir la igualdad de oportunidades $y$, en segundo lugar, por las repercusiones económicas de la actividad turística.

En un intento de conceptualizar, no es lo mismo hablar de la Accesibilidad en el turismo que hacerlo sobre Turismo accesible, propiamente dicho. El concepto de accesibilidad turística hace referencia a la cualidad de un servicio o una instalación que posibilite su uso y disfrute por cualquier persona, con independencia de su capacidad física, sensorial, psíquica o cognitiva.

Con el concepto de turismo accesible, nos deberíamos referir estrictamente a las actividades de un grupo de establecimientos y empresas turísticas que venden y promocionan también la accesibilidad integral y, especialmente, están volcados a una clientela de personas (y familiares) con discapacidades. Representan un porcentaje muy reducido todavía en comparación con el conjunto de la oferta turística convencional

No obstante, el concepto de turismo accesible tiende a generalizarse y confundirse con el de accesibilidad turística, para definir aquella tipología turística que persigue la supresión de barreras a las personas con discapacidad. En este sentido, va más allá de los equipamientos turísticos de carácter empresarial (hoteles y restaurantes, principalmente), y se amplía también a equipamientos públicos (museos y centros de recepción), a elementos naturales (playas y espacios protegidos y de recreo) y a destinos turísticos (cascos históricos).

Sin duda, a los atractivos que puedan tener los equipamientos y destinos turísticos se añade cada vez más la accesibilidad integral: una consistente ventaja que puede hacer decantar sus reservas a una potencial clientela desde sus lugares de residencia, aprovechando las nuevas tecnologías de información y comunicación.

En realidad, esta tipología de turismo accesible no debería existir como tal, de haber una plena accesibilidad en todos los espacios turísticos públicos y privados y en los diferentes modelos y tipologías turísticas (modelo de sol y playa, turismo rural, turismo cultural, de naturaleza, etc.). Todos estos modelos pueden y deberían llevar también la 
etiqueta de "accesible". De ser así, hablaríamos de un turismo de sol y playa accesible o de un turismo rural accesible, etc. Pero la realidad es que todavía no se ha alcanzado esa deseada situación (de ahí que el turismo accesible).

Dada su naturaleza, es un fenómeno o modelo turístico difícil de medir, ya que no existen estadísticas específicas precisas que lo computen. No obstante, y a pesar de esta dificultad, es significativa la importancia que adquiere el turismo accesible, especialmente en los países desarrollados, como lo muestran:

- La proliferación de políticas y leyes en favor de la accesibilidad y la integración social provenientes de diferentes escalas.

- El aumento de servicios telemáticos de gestión de la oferta pensados especialmente para este segmento turístico.

- La aparición de redes, plataformas y asociaciones que aúnan voluntades públicas y sociales y objetivos empresariales en favor del turismo accesible.

- La proliferación de experiencias empresariales que se vuelcan en la accesibilidad, la formación y la discapacidad (Turismo accesible).

- La multiplicación de foros, encuentros y jornadas.

- La importancia de la población con discapacidad (familias y hogares). Existe un segmento poblacional y social (un 9\% en España -3,7 millones de personas-, un $9,6 \%$ en Andalucía $-0,7$ millones-, y un $10 \%$ en la UE -50 millones), con capacidad de movimiento y sensorial reducido; luego, con distintos márgenes de dependencia, que, al margen de las legislaciones, tienen unas necesidades de ocio y turismo crecientes.

- Falta de formación en discapacidad y accesibilidad de muchos profesionales del turismo y de diversos servicios públicos.

- La eliminación de barreras (arquitectónicas y sociales) y la mejor formación puede ser también un nicho laboral o yacimiento de empleo que beneficiaría a múltiples trabajadores (con o sin discapacidad) y ocupaciones que de alguna manera intervienen en la prestación de servicios turísticos y de ocio.

- El turismo accesible es transversal a otras tipologías y modelos turísticos (sol y playa, rural, de naturaleza, etc.).

En este sentido, la información y el espacio virtual 2.0 se convierten en importantes aliados de este turismo accesible, en cuanto a sus objetivos y fines sociales $y$ empresariales. A golpe de ratón, aprovechando las nuevas tecnologías de información y comunicación, esta potencial clientela puede decantar sus reservas hacia equipamientos y destinos turísticos que muestren y vendan la accesibilidad integral, y no tanto por otros atractivos que tengan.

En su vertiente reducida (empresas turísticas) o amplia (destinos turísticos), el turismo accesible ofrece unas serie de ventajas respecto al convencional. No obstante, son las empresas y servicios turísticos, libremente, quienes tienen la potestad de apostar por

ISSN: 0212-8594 ISSN-e: 2340-2776.№ DOI: http://dx.doi.org/10.12795/rea.2014.i31.01

REA 31 (2014):1-34

http://www.publius.us.es/estudios_andaluces 
cumplir sólo con las exigencias que obliga la legislación en materia de accesibilidad o por volcarse en la potencial clientela de personas con discapacidades y sus familiares. En cualquier caso, el turismo accesible tiene una serie de ventajas generales a tener en cuenta (Consejería de Turismo, Comercio y Deportes, 2006):

- El turismo es un factor de integración o inclusión social. El turismo accesible de personas con discapacidad y personas mayores es un derecho para todos/as y es también una oportunidad de negocio.

- Los colectivos con discapacidad no eligen un tipo de alojamiento específico en función de su nivel adquisitivo, sino en función del nivel de accesibilidad que ofrezca el alojamiento en sí.

- Es un segmento "multicliente", en el sentido de que buena parte de los turistas con discapacidad vienen acompañados por otras personas (familiares y amigos) sin discapacidad, por lo que su repercusión económica se multiplica.

- Favorece la desestacionalidad ya que son muchas las personas con discapacidad que laboralmente son inactivas (pensionistas por discapacidad, jubilados, etc.), por lo que disponen de tiempo para viajar durante todo el año. La captación de este colectivo (turismo social) contribuye a mejorar la cuota de mercado y la rentabilidad de alojamientos y destinos turísticos accesibles, especialmente en meses de menor demanda.

- Mejora la imagen y competitividad del sector, a través de la incorporación de la accesibilidad turística en el contexto de la calidad. La accesibilidad es un valor de calidad diferenciador.

- Como consecuencia del gasto y los especiales servicios que necesitan, el turismo accesible es generador de empleo. Se abre la posibilidad de nuevos yacimientos de empleo por la diversificación y mejora de la oferta turística (tratamientos corporales, actividades de ocio activo, asistencias personales, acompañamientos, peluquería, belleza, excursiones, etc.).

- El T.A. es un acicate para mejorar la formación de personas vinculadas directa o indirectamente a la prestación de servicios públicos, turísticos y comerciales. Sólo para el caso de Andalucía, de realizarse cursos de formación que refuercen los conocimientos de la accesibilidad, la discapacidad y, con ello, las posibilidades de mejorar sus actividades turísticas, podría ascender el número de potenciales personas a formar a no menos de 30.000 alumnos, incluyendo sólo a trabajadores de establecimientos turísticos ${ }^{17}$.

- El T.A. es idóneo para la contratación de personas o trabajadores con alguna discapacidad y precisamente la legislación promueve su empleo. Asimismo, la referida formación vendría bien que la impartiesen personas con discapacidad o vinculadas al referido asociacionismo.

\footnotetext{
${ }^{17}$ Con datos de 2010 se ha tomado el número de establecimientos totales en Andalucía: 16.867. Se han barajado diferentes coeficientes de necesidades de formación según el tipo de establecimiento, llegándose al coeficiente medio de 1,68 trabajadores por establecimiento.
}

ISSN: 0212-8594 ISSN-e: 2340-2776.№ DOI: http://dx.doi.org/10.12795/rea.2014.i31.01

REA 31 (2014):1-34

http://www.publius.us.es/estudios_andaluces 


\section{ANÁLISIS DE ALGUNAS EXPERIENCIAS DE TURISMO ACCESIBLE.}

Como consecuencia del interés económico que suscita el potencial turístico de la población con discapacidad, junto a las imposiciones del conjunto de normativas y legislaciones procedentes de diferentes escalas, en los últimos años crecen las experiencias en turismo accesible.

Si bien la mejora de la accesibilidad turística se acrecienta en la oferta y destinos convencionales, no son tan numerosas las experiencias en turismo accesible, en el sentido estricto que referíamos, es decir: equipamientos públicos y privados que otorgan a la accesibilidad un plus de atención por encima de los mínimos que confiere la legislación y, en segundo lugar, porque especialmente piensen o se dirijan a la demanda del colectivo de personas con discapacidades y familiares.

Cabe hacer una tipología de las experiencias según diversas temáticas, aunque igualmente hay que subrayar y reiterar el carácter transversal de las actuaciones e iniciativas. Con esta dificultad, en adelante llevaremos a cabo distintas reflexiones sobre las siguientes temáticas:

- Actuaciones en favor de la promoción de la accesibilidad y el T.A.

- Actuaciones en favor de la accesibilidad de entornos y destinos turísticos.

- Actuaciones en favor de la concienciación y la formación en T.A.

- Actuaciones de carácter empresarial: alojamientos, agencias de viaje y otros servicios turísticos.

- Accesibilidad y nuevas tecnologías.

Como decíamos, si bien la mejora de la accesibilidad se acrecienta en la oferta y destinos turísticos convencionales, no son tan numerosas las experiencias en turismo accesible en sentido estricto: es decir, en equipamientos públicos y privados que otorgan a la accesibilidad un plus de atención por encima de los mínimos que confiere la legislación y, en segundo lugar, que especialmente piensen o se dirijan al colectivo de personas y familiares con discapacidades.

Recopilar todas y cada una de las experiencias de turismo accesible es un trabajo desbordante. Por ello, siguiendo la clasificación anterior, se han recogido valiosas experiencias, haciendo una muy breve semblanza descriptiva y valorativa de las mismas. Andalucía es el ámbito prioritario; no obstante, algunas de las mismas proceden originariamente de otras escalas, aunque también tienen su aplicación en este territorio.

Por otra parte, la mayoría de estas experiencias cuentan con páginas y plataformas webs, dado que es fundamental el objetivo de difundir globalmente la información de las actuaciones públicas o privadas. Sin duda, esta extensión de la información tiene un 
sentido práctico y es el de ampliar el ámbito de influencia y de mercado, para una potencial clientela, a escalas globales.

\subsection{ACTUACIONES EN FAVOR DE LA PROMOCIÓN DE LA ACCESIBILIDAD Y EL T.A.}

Las actuaciones en torno a la promoción de la accesibilidad y el T.A. son muy numerosas, provenientes especialmente de las muchas asociaciones y plataformas de personas con discapacidades, empleando especialmente la información de sus webs.

- Guía de accesibilidad de la Plataforma Representativa Estatal de Discapacitados Físicos (PREDIF).

Esta institución (http://www.predif.org/) recientemente ha publicado una magna obra de más de 600 páginas con 167 monumentos y museos relevantes por las obras de acondicionamiento técnico, además de su importancia cultural y turística. Para el caso de Andalucía se destacan 27 de los mismos.

Figura 1. Guía de accesibilidad de la Plataforma PREDIF.

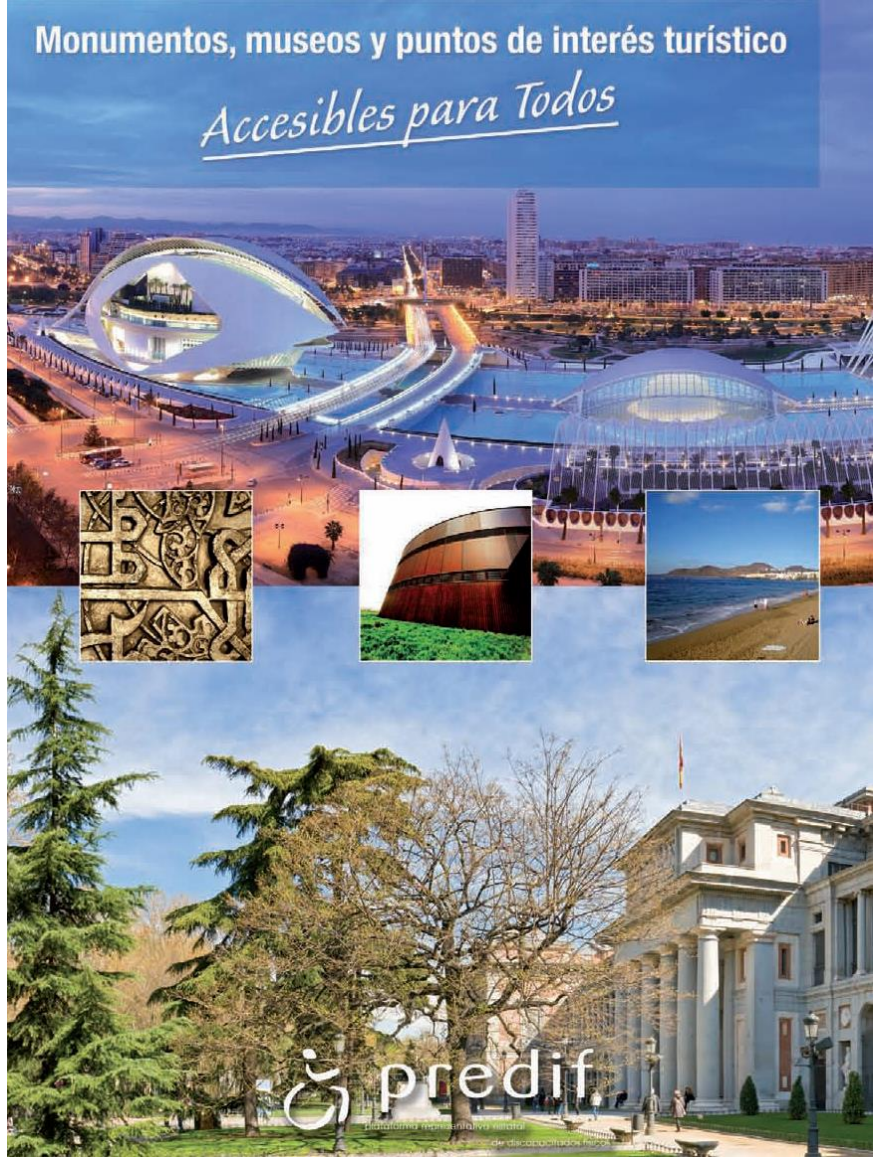

Fuente: PREDIF (2010): Guía de monumentos, museos y otros puntos de interés accesibles para todos; ver en http://www.españaescultura.es/export/sites/cultura/publicos/guias_accesibil idad/Monumentos_Museos_Accesibles.pdf

ISSN: 0212-8594 ISSN-e: 2340-2776.No DOI: http://dx.doi.org/10.12795/rea.2014.i31.01 REA 31 (2014):1-34 
- Guía de turismo accesible en la ciudad de Sevilla.

El Consorcio de Turismo del Ayuntamiento de Sevilla y la Asociación Andaluza para la Discapacidad (http://www.valinet.org) editaron en 2005 esta Guía (http://discapacidadsevilla.org/gdas/turismo_accesible.html). Consta de una selección de hoteles, restaurantes, cines y teatros, parques y jardines, itinerarios, estacionamientos y otros servicios accesibles. Se completa la información con la dirección postal, teléfono de contacto, fax y sitio web además de la ubicación en un plano que acompaña la guía.

- Página web especializada en turismo accesible de Jaén.

La Federación Provincial de Asociaciones de Personas con Discapacidad Física y Orgánica de Jaén (http://www.fejidif.org/ y http://www.jaenaccesible.org/) crea y mantiene este importante Portal de Turismo Accesible para personas con movilidad reducida. Tienen una guía de accesibilidad de los establecimientos tanto públicos como privados. En una amplia base de datos, se analiza desde los establecimientos hoteleros hasta los edificios públicos, desde los centros de cultura y ocio hasta las instalaciones deportivas, desde las plazas y jardines hasta las rutas y senderos rurales. Su web contiene una generosa documentación referente al turismo accesible (aspectos técnicos y sociales, legislación, planes, etc.) perfectamente descargables y consultables. Esta experiencia, que arranca de una provincia interior como es Jaén, podría extenderse a otros territorios.

- Estrategia de Turismo Accesible, "Linares para To2".

Linares (Jaén) se convierte en otro municipio de interior que intenta revalorizar sus atractivos turísticos, especialmente pensando en el turismo accesible (http://www.ciudaddelinares.es). De ahí que desde el ayuntamiento hayan confeccionado una "Guía turística accesible de Linares", han instalado una señalización turística accesible en los principales monumentos de la ciudad, han elaborado dos paquetes turísticos inclusivos -cultural y activo-, que están siendo promocionados en internet y redes sociales, han reforzado la acción formativa de trabajadores del ayuntamiento vinculados directa o indirectamente con la atención al público y con el sector turístico y están motivando a los empresarios para participar activamente en materia de accesibilidad.

- Celebración de congresos, encuentros y foros.

En los últimos años se han multiplicado los foros, encuentros y jornadas sobre accesibilidad, discapacidad y turismo accesible, en los que se promocionan la accesibilidad como elemento muy importante para todas las tipologías turísticas. Recientemente, cabe destacar el Foro sobre accesibilidad, turismo y nuevas tecnologías, celebrado en febrero de 2012 en Marbella o el Primer Congreso 
Internacional "Viajar con Discapacidad", celebrado en marzo de 2012 en Jaén. Asimismo, la ONCE organiza desde 2004 y con una periodicidad trianual congresos con el lema "Turismo para todos". El primero se organizó en Islantilla (Huelva) y en junio de 2013 fue en Ávila.

\subsection{ACTUACIONES EN FAVOR DE LA ACCESIBILIDAD DE ENTORNOS Y DESTINOS TURÍSTICOS.}

Bajo este epígrafe cabría englobar un conjunto numeroso de actuaciones en accesibilidad turística de diferentes administraciones públicas en los espacios urbanos, en edificios de interés patrimonial y turístico, museos o en espacios de interés recreativo como playas, miradores, centro de visitantes, etc.

Existe una ingente literatura sobre las condiciones técnicas de la accesibilidad en los espacios y entornos naturales. De igual manera, hay interesantes webs que ofrecen información sobre los espacios y entornos naturales accesibles. En este sentido, para el caso de España, destacan las webs:

- http://www.diseñoparatodos.es/eses/documentacion/bibliografia/naturales/Paginas/default.aspx

- http://www.jaenaccesible.org/documentacion/documentacion/Medio\%20ambi ente/Catalogo\%20de\%20buenas\%20practicas\%20en\%20espacios\%20naturales. pdf

Existe también una amplia literatura sobre las condiciones técnicas de la accesibilidad en playas. Asimismo, hay potentes webs que sirven de información sobre las posibilidades de información de las playas accesibles en España. En este sentido destacan las webs: http://playasaccesibles.discapnet.es/ del Observatorio Estatal de la Discapacidad. Según esta fuente, España dispone de unas 600 playas accesibles. Asimismo, la web de Confederación Andaluza de Personas con Discapacidad Física y Orgánica (CANF-COCEMFE Andalucía http://www.canfandalucia.org) informa también del estado de accesibilidad de las playas andaluzas.

La accesibilidad al patrimonio construido centra gran parte de la cuestión. Existen cientos de ejemplos pertenecientes al patrimonio histórico artístico edificado en Andalucía que no pueden ser conocidos por su falta de accesibilidad. La accesibilidad turístico-patrimonial no se limita a la vertiente física, no se soluciona exclusivamente con la instalación de rampas de acceso y ascensores, sino que debe extenderse a otras parcelas sensoriales a través de audioguías, maquetas y elementos táctiles, etc.

\section{- Playas accesibles.}

El papel de los municipios en la adecuación del mobiliario de playas de cara a la mejor accesibilidad es fundamental. De esta manera, algunos municipios incluso han conseguido reconocidos galardones como la Norma UNE 170001. Para el caso de 
Andalucía obtienen esta mención las siguientes playas ${ }^{18}$ : Playa de La Antilla (LepeHuelva) y playas de El Dedo, Pedrejalejo y de la Misericordia en el municipio de Málaga.

Foto 1. Mejora de la accesibilidad en Playa de La Antilla (Huelva).
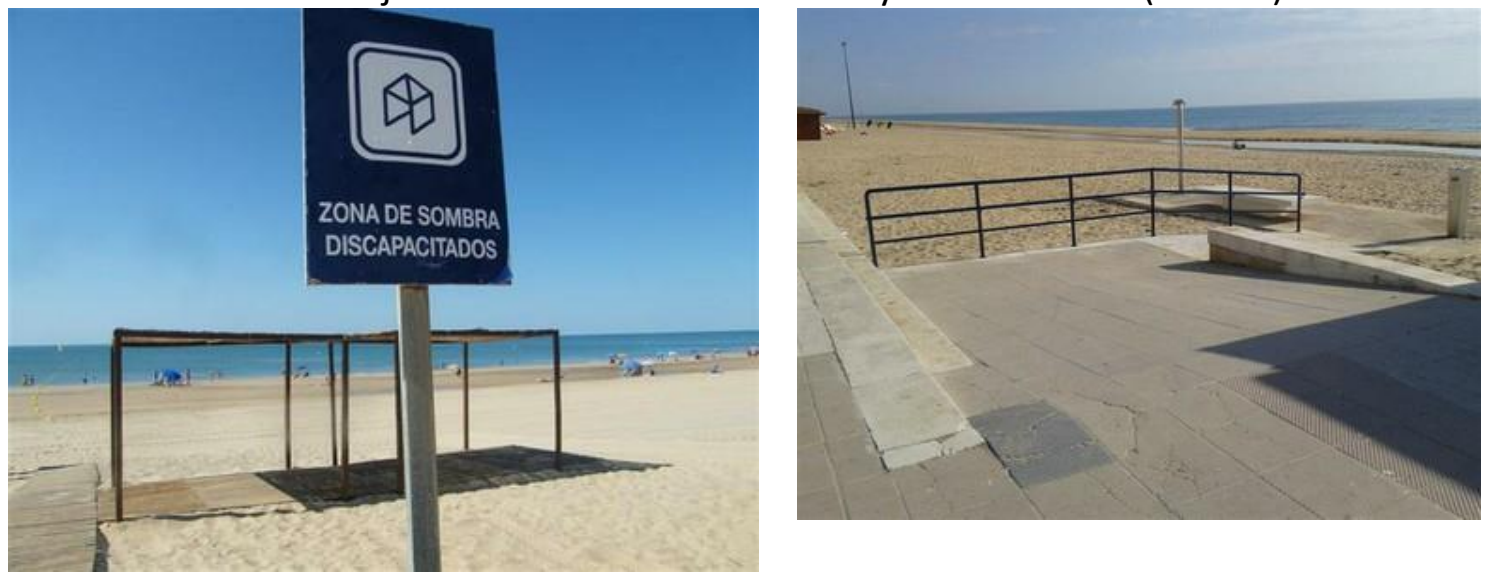

Fuente: Ayuntamiento de Lepe; Ver en:

http://www.lepe.es/turismo/copy_of_playas/accesibilidad/equipamiento-accesible

- Actuaciones del Ministerio de Medio Ambiente. Dirección General de Costas y Medio Marino.

Desde 2001 la Dirección General de Costas y Medio Marino (http://www.magrama.gob.es/es/costas/temas/default.aspx) tiene un plan de accesibilidad costera que ha permitido que las playas accesibles en España se hayan multiplicado.

- Portal de las Personas con Discapacidad-Discapnet-.

El Portal Discapnet (http://playasaccesibles.discapnet.es/) detecta en España más de 600 playas accesibles. Así, los destinatarios de la guía de playas accesibles podrán buscar costas sin barreras por comunidades o provincias y saber qué servicios y recursos de accesibilidad ofrecen. La guía especifica los servicios adaptados con los que cuenta cada playa y si hay o no en ella personal de apoyo al baño. Recoge, además, comentarios o informaciones complementarias de interés.

\footnotetext{
${ }^{18}$ Consejería de Turismo y Comercio.

http://www.juntadeandalucia.es/turismoycomercio/opencms/organigrama/consejero/viceconsejeria/tu rismo/calidad/establecimientos-espacios-certificados/buscador-establecimientos/establecimientos.jsp
}

ISSN: 0212-8594 ISSN-e: 2340-2776.№ DOI: http://dx.doi.org/10.12795/rea.2014.i31.01

REA 31 (2014):1-34

http://www.publius.us.es/estudios_andaluces 
- Obras de accesibilidad en espacios naturales de Andalucía ${ }^{19}$.

La ahora Consejería de Agricultura, Pesca y Medio Ambiente (http://www.juntadeandalucia.es/medioambiente/site/portalweb/)de la Junta de Andalucía ha realizado múltiples obras de mejora de la accesibilidad en sus espacios naturales, en miradores, senderos, señalización y centros visitantes. A ello se une los programas de visitas ("Naturaleza para Todos") ${ }^{20}$ que mantiene con colectivos, entre otros, de personas con discapacidad.

Foto 2. Accesibilidad en espacios naturales de Andalucía

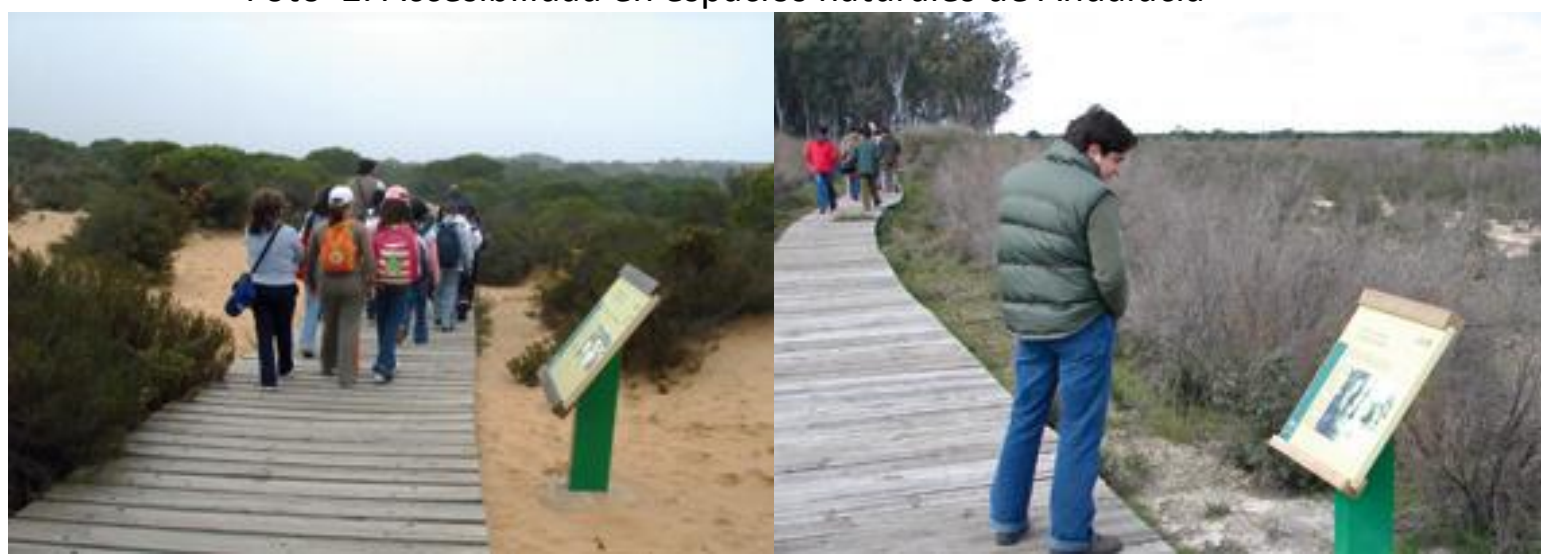

Fuente: Consejería de Agricultura, Pesca y Medio Ambiente (2008). Guía de recursos didácticos de la provincia de Huelva. Junta de Andalucía; ver en:http://www.juntadeandalucia.es/medioambiente/servtc5/ventana/publicacionesCategoria.do;jse ssionid=E8745C76EFB611EBEF827C6B47A725D0?tipo=PR\&sel=HUELVA

\subsection{ACTUACIONES EN FAVOR DE LA CONCIENCIACIÓN Y LA FORMACIÓN EN T.A.}

Los turistas con discapacidad tienen unas necesidades específicas que varían en razón a su discapacidad. En la obra "Decálogo de buenas prácticas en accesibilidad" (2009) de la Secretaría General de Turismo ${ }^{21}$, hay todo un "Manual de atención a personas con discapacidad", con recomendaciones generales y específicas para cada tipo de discapacidad.

No se puede construir una accesibilidad integral en equipamientos y productos turísticos sin que se mejore la formación de las personas que trabajan o se vayan a dedicar al turismo. La formación de los profesionales que puedan prestar servicios

\footnotetext{
19 La obra "Espacios y actividades en la naturaleza; accesibles para todas las personas", editada por PREDIF (http://www.spain.info/turismo-accesible/guias/Guia_Parques_Naturales.pdf) se recogen con detalle una treintena de equipamientos en espacios naturales de Andalucía accesibles

${ }^{20}$ Consejería de Agricultura, Pesca y Medio Ambiente. Ver en:

http://www.juntadeandalucia.es/medioambiente/servtc5/ventana/actividades.do

${ }^{21}$ Ver en: http://www.planaccesibilidadturistica.es/publicaciones.php?id_actual=39
}

ISSN: 0212-8594 ISSN-e: 2340-2776.№ DOI: http://dx.doi.org/10.12795/rea.2014.i31.01

REA 31 (2014):1-34

http://www.publius.us.es/estudios_andaluces 
turísticos aunque no debe variar mucho de turistas sin discapacidades, sí que ha de conocer algunas atenciones y tratos en razón a las discapacidades existentes.

Asimismo, esta formación complementaria no debe extenderse sólo a los trabajadores y jóvenes estudiantes sino también a los empresarios y responsables de establecimientos turísticos para conocer aspectos técnicos y legales que surgen en torno al T.A. Así pues, se han multiplicado los cursos formativos en esta disciplina, auspiciados principalmente por asociaciones de personas con discapacidad. Entre estas experiencias, destacan:

\section{- La Asociación FEJIDIF.}

La Federación Provincial de Asociaciones de Personas con Discapacidad Física y Orgánica de Jaén (http://www.fejidif.org/ y http://jaenaccesible.org/turismoac/) también es pionera en este tipo de cursos que se realiza en régimen semipresencial.

- Real Patronato de la Discapacidad.

El Real Patronato sobre la Discapacidad (www.rpd.es) pone a disposición de las Escuelas Universitarias de Turismo de toda España los Cursos de Formación en turismo accesible. Su finalidad es dotar a los estudiantes, futuros trabajadores y gestores de todos los eslabones de la cadena turística, de conocimientos y formación que potencie la accesibilidad universal en materia turística.

\section{- Red Española de Turismo Accesible - Red Estable.}

Esta Red (http://www.redestable.com/) está constituida actualmente por empresas repartidas por 10 comunidades autónomas, con una larga y reconocida experiencia en el ámbito del desarrollo, implantación y prestación de servicios en el ámbito del turismo accesible. Tiene entre sus objetivos favorecer la integración social de personas con discapacidad. Por ello, en enero de 2012 crearon el "Manifiesto por un Turismo Accesible ${ }^{\prime 22}$. A través del mismo, Red Estable quiere sensibilizar a todos los agentes del sector turístico (públicos y privados) sobre la necesidad de contemplar e integrar la accesibilidad en sus políticas y sistemas de gestión.

- Taller de Empleo "Turismo accesible" del Instituto Municipal de Desarrollo Económico y Empleo de Córdoba (IMDEEC).

Los alumnos del Taller de Empleo "Turismo accesible" del Instituto Municipal de Desarrollo Económico y Empleo de Córdoba (IMDEEC) con la colaboración de la Oficina para la Accesibilidad de la Gerencia Municipal de Urbanismo (GMU) han realizado una "Guía accesible de Córdoba" (http://cordobaaccesible.org/). Está disponible en dos formatos: publicación impresa y formato digital en web. La guía permite consultar la información de manera flexible. Se ofrecen una serie de rutas preestablecidas a seguir,

\footnotetext{
22 "Manifiesto por un Turismo Accesible" (2012). Ver en: http://manifiesto.redestable.com/ManifiestoTurismo-Accesible.pdf
}

ISSN: 0212-8594 ISSN-e: 2340-2776.№ DOI: http://dx.doi.org/10.12795/rea.2014.i31.01

REA 31 (2014):1-34

http://www.publius.us.es/estudios_andaluces 
pero al mismo tiempo el usuario puede configurar su propia ruta y consultar la accesibilidad de las calles que haya seleccionado.

\subsection{ACTUACIONES CON CARÁCTER EMPRESARIAL: ALOJAMIENTOS, AGENCIAS DE VIAJES Y OTROS SERVICIOS TURÍSTICOS.}

El turismo accesible no es sólo una cuestión social, sino que tiene un componente económico muy importante y cada vez más presente. En este sentido, entra en juego principalmente empresas privadas que ofrecen en sus instalaciones y en sus servicios mayores prestaciones para personas con discapacidades. Por ello, sus establecimientos y sus distintos servicios son plenamente accesibles y los profesionales que trabajan en los mismos tienen una formación complementaria en lo que concierne a la accesibilidad y la discapacidad.

Por otra parte, esta actividad económica o lucrativa no es sólo de las empresas privadas, sino que se extiende también a algunas asociaciones que inicialmente surgieron sólo con un fin social. Son los casos de FEJIDIF en Jaén y "Paz y Bien" en Sevilla.

El hotel es, quizás, el equipamiento turístico por excelencia: un edificio en el que se debería incluir las máximas prestaciones de accesibilidad para garantizar el ocio y la seguridad de personas con discapacidad. Existe una amplia literatura sobre las condiciones técnicas de la accesibilidad en los hoteles ${ }^{23} \mathrm{u}$ otras instalaciones. De igual manera, hay webs que sirven de información sobre las posibilidades de información de los hoteles accesibles. En este sentido, para el caso de España, destacan las webs:

- http://www.polibeaturismo.com/

- http://www.arrakis.es/ cotton/hot/hot.htm

- http://www.predif.org/

\section{- Cadena hotelera Confortel.}

Cuando todavía no se hablaba de turismo accesible y la temática de la accesibilidad era embrionaria, la Fundación ONCE (http://www.fundaciononce.es) fue pionera en estas cuestiones. Sus hoteles (http://www.confortelhoteles.com) están pensados arquitectónicamente para personas con discapacidades, lo que no invalida, por supuesto, acoger a otras personas.

Buena parte de sus hoteles poseen la norma UNE 170.001-2 de Accesibilidad Universal. Entre los que se sitúan en Andalucía con esta distinción de calidad están los que se sitúan en Islantilla, Conil, Fungirola y Sevilla.

\footnotetext{
${ }^{23} \operatorname{Ver}$ http://www.ecom.cat/pdf/hotel_accesible.pdf
} 
Foto 3. Hotel Confortel (Islantilla).
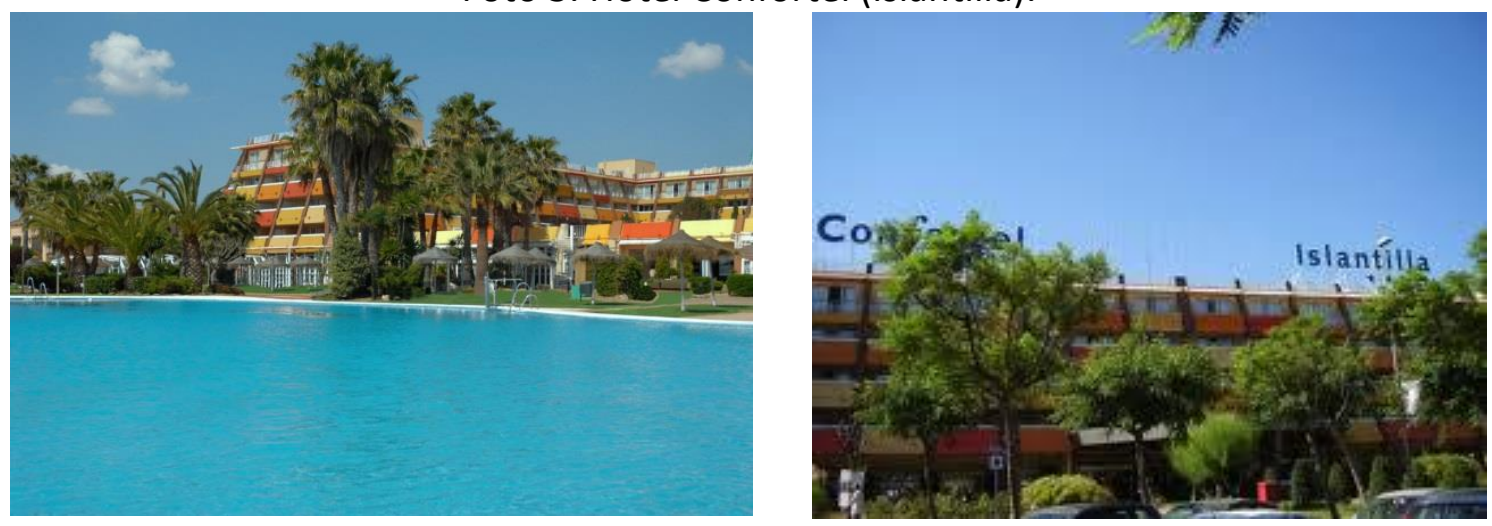

Fuente:http://www.confortelislantilla.com/

- Hotel Sierra Luz (Cortegana-Huelva).

Una de las grandes aportaciones de la Asociación Paz y Bien (http://www.pazbien.es) a este nuevo turismo accesible es el Hotel Rural "Sierra Luz", completamente adaptado para permitir el alojamiento a personas con discapacidad y dependencia y para ofrecerles actividades de ocio, conocimiento y entretenimiento. Está ubicado en la localidad onubense de Cortegana, en el Parque Natural Sierra de Aracena y Picos de Aroche, participando de los valores del turismo rural y de naturaleza de esta comarca.

Foto 4. Hotel Sierra Luz (Cortegana-Huelva).

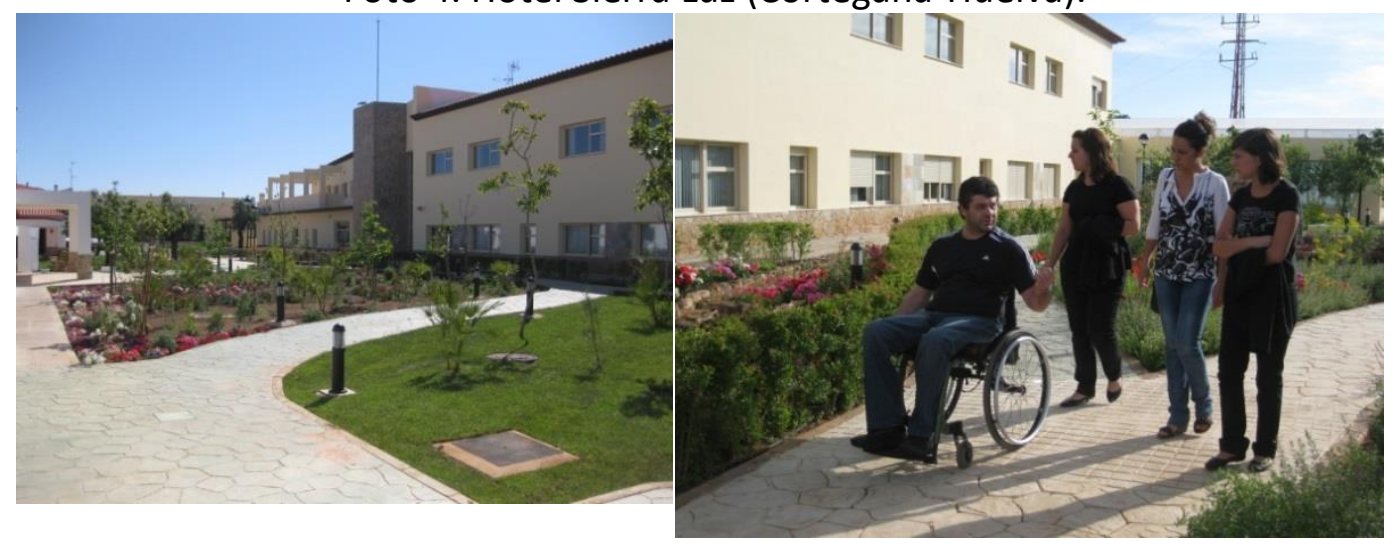

Fuente: Fernández Tristancho, A. (2011) y Asociación Paz y Bien, en http://www.pazbien.es

\section{- Fundación Polibea y Viajes 2000.}

Como hemos dicho, los fines asociativos y los intereses empresariales se dan la mano con la Fundación Polibea y Viajes 2000 (http://www.polibeaturismo.com/) que forman una agencia de viajes especialmente volcada al turismo accesible. En el interior de su plataforma Web hay información sobre la "Guía accesible del viajero" ${ }^{24}$ y “España: accesible" 25 .

\footnotetext{
${ }^{24}$ Polibea: Guía accesible del viajero. Ver en:

http://www.polibeaturismo.com/archivos/guiaAccesibleDelViajero2007.pdf
}

ISSN: 0212-8594 ISSN-e: 2340-2776.№ DOI: http://dx.doi.org/10.12795/rea.2014.i31.01

REA 31 (2014):1-34

http://www.publius.us.es/estudios_andaluces 


\section{- Grupo Almeida Viajes.}

Es un magnífico ejemplo de cómo el turismo accesible es el arranque de un éxito empresarial (http://www.almeidaviajes.com/). Fundada por una joven empresaria onubense, suma numerosos premios por su trayectoria empresarial. En pocos años se ha convertido en la primera agencia mayorista turística en España volcada esencialmente en turismo accesible para personas con discapacidad. En la actualidad, esta empresa cuenta con más de 400 oficinas repartidas por España, Portugal, México y Brasil. Además, y a pesar de la crisis, sigue abriendo oficinas y franquicias.

\subsection{ACCESIBILIDAD Y NUEVAS TECNOLOGÍAS.}

Decíamos que la inmensa mayoría de las experiencias en turismo accesible cuentan con páginas webs, dado el objetivo de difundir la información. A su vez, se han multiplicado los blogs, las redes sociales y los foros en los que se abordan principalmente la accesibilidad, la discapacidad y el turismo accesible. Asimismo, es significativo que en la mayoría de estos blogs y webs existe una visión global, que va más allá de los límites administrativos (estados, CCAA, etc.) donde se radiquen estas asociaciones y personas.

-SIG sobre Accesibilidad.

La asociación FEJIDIF gestiona un Sistema Geográfico del Medio Accesible (http://www.e-sig.info/fejidif/), con la idea de relacionar los equipamientos y espacios accesibles de una ciudad y municipio. En el mismo, el usuario puede obtener información precisa sobre el sistema viario, transportes, lugares de interés, etc. de cara a la accesibilidad y el turismo accesible.

\section{- Red Social "Sí podemos".}

La Asociación Andaluza de Trabajadores, Autónomos y Empresarios con Discapacidad "Sí podemos" mantiene una interesante Red sobre temas de accesibilidad y turismo (http://sipodemos.ideal.es/). A su vez, también posee otro portal (http://www.laciudadaccesible.com/privacidad.html) especializado en temas de arquitectura y urbanismo accesible.

- Cine y teatro accesible en Almería.

Es un buen ejemplo de que las manifestaciones artísticas también se pueden hacer accesibles a determinados tipos de discapacidad, especialmente la visual (http://almeriaaccesible.wordpress.com/author/almeriaaccesible/).

\footnotetext{
${ }^{25}$ Polibea: España: accesible". Ver en:

http://www.polibeaturismo.com/Comunidades/espanaAccesible.htm
}

ISSN: 0212-8594 ISSN-e: 2340-2776.№ DOI: http://dx.doi.org/10.12795/rea.2014.i31.01

REA 31 (2014):1-34

http://www.publius.us.es/estudios_andaluces 
- Museo provincial de Huelva. Proyecto Arqueotáctil26.

El Museo Provincial de Huelva ha realizado recientemente un trabajo para acercar los contenidos de su Sala de Arqueología a las personas con discapacidad visual a través del proyecto Arqueotáctil. El objetivo del mismo es permitir el conocimiento, mediante el tacto, de algunas de las piezas más interesantes que se exponen en este museo.

Foto 5. Proyecto Arqueotáctil del Museo provincial de Huelva
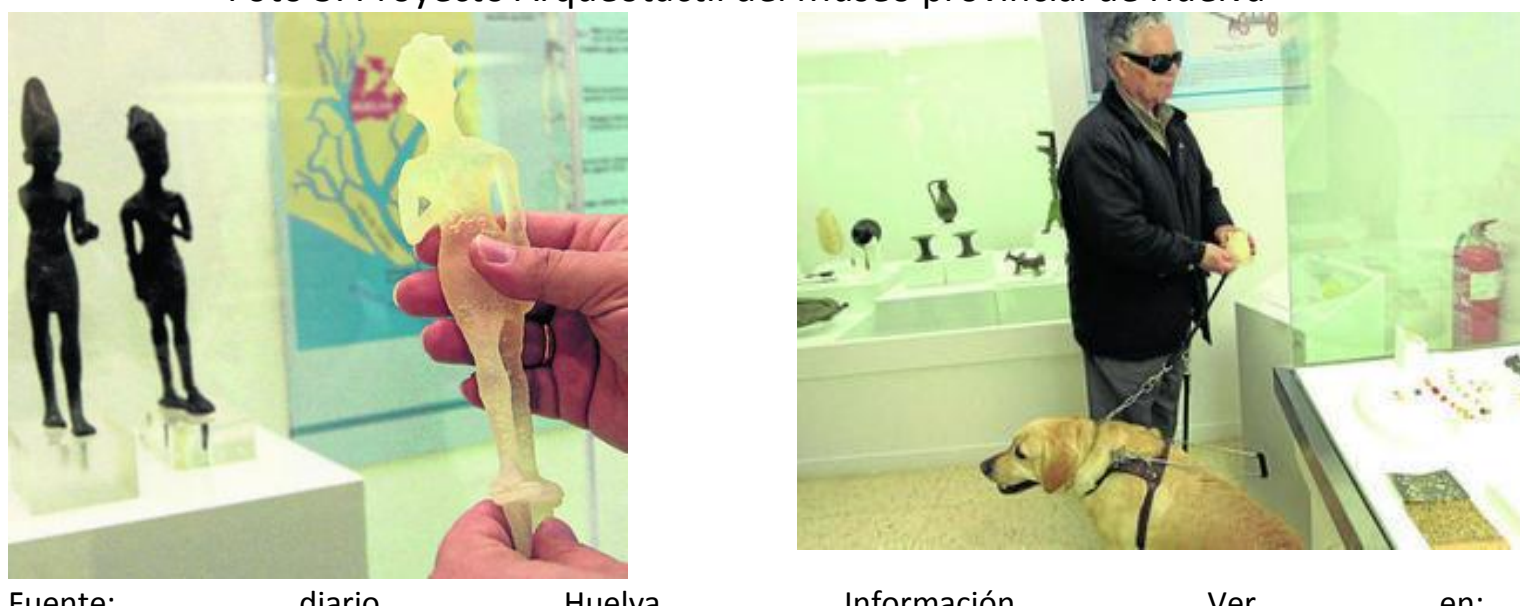

Fuente: diario

Huelva

Información.

Ver

en:

http://www.huelvainformacion.es/article/huelva/1485722/museo/provincial/mas/accesible.html\#.UUrE -1QGeo4.email

\section{CONCLUSIONES.}

La mejora de la accesibilidad en todo tipo de servicios públicos y privados, entre otros en el sector turístico, tiene unas claras y positivas repercusiones:

- Supone el acceso en igualdad de condiciones de la totalidad de la población a los recursos turísticos, es decir que es un derecho fundamental del ciudadano y así está recogido por un amplio, aunque reciente, compendio legislativo.

- Es un factor de suma importancia para la plena integración de un emergente y creciente segmento de mercado turístico: el de las personas con discapacidad.

A estos aspectos hay que añadir la relevancia del número de personas con alguna discapacidad sensorial en Andalucía, España o la Unión Europea, en torno al 10\%. Se trata de una población en aumento como consecuencia del envejecimiento demográfico, que desea gozar del ocio, así como adquirir servicios turísticos. Por tanto, a la necesaria imposición legislativa sobre estos equipamientos habría que añadir la potencialidad económica de esta demanda turística, y que justifica también la

\footnotetext{
${ }^{26}$ Información obtenida del diario Huelva Información. Ver en:http://www.huelvainformacion.es/article/huelva/1485722/museo/provincial/mas/accesible.html\#.U UrE-1QGeo4.email
}

ISSN: 0212-8594 ISSN-e: 2340-2776.N№ DOI: http://dx.doi.org/10.12795/rea.2014.i31.01 REA 31 (2014):1-34 
adopción de medidas en materia de accesibilidad y formación por parte de las empresas y organismos ligados al turismo.

Por otra parte, se trata de un segmento de la población que cuenta con ciertas características muy interesantes para el sector turístico. Por un lado, las personas con un mayor grado de dependencia siempre viaja acompañado, muchas veces en grupos, por lo que el tamaño medio de este tipo de turistas es superior a la media. Por otro lado, al tratarse de un segmento emergente, en el que la oferta es aún limitada, es un cliente fácil de fidelizar si la oferta cubre sus expectativas y necesidades (no es nada infrecuente que aquello que se anuncia o vende como accesible no lo sea realmente), y al tratarse de un grupo social con una gran tendencia al asociacionismo, el boca a boca tiene una gran repercusión. Por último, al tratarse de turistas con necesidades especiales, la preparación del viaje se suele hacer con mucha mayor antelación, bien planificadas y, por tanto, que demanda unos servicios de organización e información especializados.

Los espacios turísticos de España y, dentro de la misma, Andalucía, indudablemente, reúnen recursos patrimoniales y naturales que los hacen ser muy atractivos para la actividad turística y sus distintos modelos o tipologías. De hecho, buena parte de sus economías, y especialmente, de algunos de sus territorios, están influenciadas directa o indirectamente por el turismo, un sector, de por sí, de enorme transversalidad: infraestructuras, transportes, medio ambiente, economía, patrimonio natural y cultural, etc. Dentro de su amplia y diversa demanda turística, un colectivo creciente es el de personas mayores y el de personas con distintas discapacidades sensoriales y motrices que necesitan contar, además de otros atractivos, con el factor de la accesibilidad. Por tanto, cada vez más, se convierte en un elemento esencial que puede justificar la opción final de estos potenciales turistas $y$, por ende, tiene una repercusión en la rentabilidad de equipamientos y destinos turísticos.

Queda claro, y así lo demuestran las encuestas turísticas ${ }^{27}$ que si se quiere apostar por la calidad del producto turístico, en cualquiera de sus tipologías, modelos y destinos, es necesario hacerlo también por la accesibilidad integral. De las enormes posibilidades económicas que brinda este segmento poblacional y turístico han de ser conscientes todas las administraciones, en cualquiera de sus escalas, y sobre todo el tejido empresarial volcado en actividades de la hotelería y hostelería, así como también los subsectores del transporte y el comercio.

Como consecuencia de ello, crece un modelo turístico que ha dado en llamarse "turismo accesible" que, en realidad, no debería ser un modelo, frente a otros, de

\footnotetext{
27 CONSEJERÍA de Turismo, Comercio y Deportes (2010): Encuesta II Plan de Calidad Turística de Andalucía. $\quad$ Ver en: http://www.juntadeandalucia.es/turismocomercioydeporte/export/sites/ctcd/archivos/prensa/Present acixn_Plan_de_Calidad.pdf
}

ISSN: 0212-8594 ISSN-e: 2340-2776.№ DOI: http://dx.doi.org/10.12795/rea.2014.i31.01

REA 31 (2014):1-34

http://www.publius.us.es/estudios_andaluces 
alcanzarse la accesibilidad en todos los equipamientos y espacios de uso público y atracción turística. Pero la realidad dista todavía de ese deseo. Por ello, se convierte, de alguna manera, en un nuevo producto o tipología dada su mayor apuesta por la accesibilidad y la discapacidad frente a la oferta de otros modelos de turismo convencional (sol y playa, rural, etc.).

Al posible interés económico, se unen razones de integración y justicia social de la población con discapacidades, que la legislación intenta eliminar después de siglos de barreras físicas y mentales hacia la discapacidad. Por ello, el turismo accesible está íntimamente asociado a los conceptos de accesibilidad integral y discapacidad/integración social.

A pesar de los avances habidos en los últimos años, con una mayor sensibilización social, queda mucho por hacer o por hacer cumplir en cuanto a la accesibilidad integral o universal y con respecto a este importante colectivo con algún tipo discapacidad pero con los mismos derechos sociales y aspiraciones de ocio y turismo. Las medidas que se tomen para conseguir una accesibilidad idónea contribuirán a aumentar la calidad de vida de todos los usuarios.

Nuestras administraciones públicas, turísticas o de otro tipo, creadoras de un ingente maremagno legislativo y normativo, y a diversas escalas territoriales, son también responsables de hacer cumplir los requisitos legales. No obstante, no pocas veces suspenden en asegurar la accesibilidad de las infraestructuras y servicios públicos, en exigir el cumplimiento de normativas a los entes privados y en sancionar las infracciones. Otro importante hándicap es el escaso seguimiento en el cumplimiento de las medidas requeridas para garantizar la accesibilidad. No basta con la exigencia de ciertas medidas en el momento de solicitar un permiso o licencia, sino también que estos requerimientos se mantengan en el tiempo para que la accesibilidad sea real.

También ha de prestarse especial atención a la calidad de la información o de las medidas que se llevan a cabo desde las administraciones. En este sentido, destaca que en ocasiones la accesibilidad se queda sobre el papel, en el diseño o proyecto de determinadas obras y actuaciones, pero luego en la ejecución no siempre es real o funcional. También es fundamental una buena planificación y coordinación de las adecuaciones. Por ejemplo en la adecuación de senderos o accesos a playas y espacios naturales, pero que luego carecen de servicios adaptados.

El tejido empresarial turístico igualmente tiene muchos retos por delante. La accesibilidad no se resuelve sólo con incorporar una rampa en el acceso del comercio, restaurante $u$ hotel. Es un concepto más amplio que conlleva también una concienciación e implicación personal, laboral y empresarial más amplia. Ello exige compromisos empresariales hacia el turismo accesible -en el sentido estricto que comentábamos- que todavía sólo en contadas iniciativas es palpable y manifiesto.

ISSN: 0212-8594 ISSN-e: 2340-2776.N№ DOI: http://dx.doi.org/10.12795/rea.2014.i31.01

REA 31 (2014):1-34

http://www.publius.us.es/estudios_andaluces 
Pero no todo es cuestión de soluciones técnicas ("diseños para todos"). La accesibilidad, la integración social y el turismo accesible es fruto también de una formación que es necesario ampliar y mejorar. En este sentido, para el sector turístico es muy importante dado que sus profesionales actuales y futuros están volcados fundamentalmente en la prestación de servicios personales

Es necesaria una nueva cultura de lo accesible y la discapacidad. Primero, por cuestiones sociales, pero también porque la supresión de barreras tiene implicaciones económicas, entre otras, en el turismo; en las que son un valor añadido. Si queremos un sector turístico de calidad no se puede dejar al margen a las personas con discapacidad y las numerosas barreras que siguen encontrando. Sin duda, el turismo accesible es el nexo o la llave, para alcanzar de forma real un turismo para "Todas las personas". Precisamente, esta vertiente social es también esencial para considerar una actividad turística como verdaderamente "sostenible".

A pesar de que resta mucho por hacer, el turismo accesible es un fenómeno creciente y de enormes potencialidades. Sin embargo, curiosamente, todavía está muy poco estudiado, especialmente desde el campo de la geografía. De cualquier ámbito territorial o modelo turístico, podrían realizarse múltiples estudios e investigaciones. Por tanto, sirva este trabajo para dar a conocer la especial naturaleza de este modelo o tipología turística que, como decíamos, es transversal a otros y que, al mismo tiempo, se puede fomentar en cualquier territorio.

\section{BIBLIOGRAFÍA}

ACTUAN Programa Euroempleo (2012): El turismo accesible en Andalucía y Portugal. Buenas prácticas y potencialidades para el empleo. Proyecto Euroempleo "Turismo accesible: un nuevo yacimiento de empleo". Consejería de Empleo, Junta de Andalucía. 265 págs.; en:

http://www.actuan.es/index.php/documentacion/publicaciones/doc_details/33-librode-buenas-practicas-y-trabajos-desarrollados.html

Alonso López, F. (1999): Los beneficios de renunciar a las barreras. Instituto de Mayores y Asuntos Sociales (IMSERSO). Secretaría General de Asuntos Sociales. Ministerio de Trabajo y Asuntos Sociales. Madrid.

Alonso López, F (2002): Libro Verde de la accesibilidad en España. Imserso-Acceplan; en http://www.ceapat.es/InterPresent1/groups/imserso/documents/binario/libroverded elaaccesibilidadene.pdf 
Alonso, F. y Dinarés, M. (2006): El hotel accesible. Guía para su diseño, organización y gestión. Colección Manuales y Guías Serie Servicios Sociales. Ministerio de Trabajo y Asuntos Sociales. IMSERSO; en:

http://www.imserso.es/InterPresent2/groups/imserso/documents/binario/hotelaccesi ble.pdf

Brinckmann, W. E. y Wildgen, J. S. (2003): “Desafíos para los estudiosos del turismo: La construcción de la sociedad inclusiva y del turismo accesible", en Cuadernos de Turismo, no 11, pp. 41-58. Universidad de Murcia; en http://revistas.um.es/turismo/article/view/19621

Brown, F. (1991): "Tourism for All”, en Tourism Management, vol. 12, no 3, pp. 258260.

Buhalis, D.; Eichhorn, V.; Michopoulou, E.; Millar, G. (2005): Accessibility Market and Stakeholder Analysis. University of Surrey/One Stop Shop for Accesible Tourism in Europe (OSSATE).

Burnett, J. J. y BAKER, B. H. (2001): "Assessing the Travel Related Bahaviours of the Mobility Disabled Consumer", en Journal of Travel Research, 40 (1), 4-11.

Burnett, J.J. (1996): "What services marketers need to know about the mobilitydisabled consumer", en The Journal of Services Marketing, Vol. 1ㅇ, nㅇ, 3, pp. 3-20.

Centi, S.; Mossone, M.C.; Borghetti, J.; Tramonti, E. (2004): Accesible Tourist Product. (Proyecto Eu.For.Me financiado por la Unión Europea).

Comité Económico y Social de la U.E. (2008): Dictamen sobre Turismo Social en Europa. Diario Oficial de la Unión Europea. 2006/C 318/12; en http://eurlex.europa.eu/LexUriServ/LexUriServ.do?uri=OJ:C:2006:318:0067:0077:ES:PDF

Comité Español de Representantes de Personas con Discapacidad (CERMI) (2003): Plan de Acción del CERMI de Turismo Accesible para todas las Personas. Madrid; enhttp://www.cocemfeasturias.es/14/60/161/doc-1.htm

Consejería de Medio Ambiente (2008): Guía de recursos didácticos de la provincia de Huelva. Junta de Andalucía; en:

http://www.juntadeandalucia.es/medioambiente/servtc5/ventana/publicacionesCateg oria.do;jsessionid=E8745C76EFB611EBEF827C6B47A725D0?tipo=PR\&sel=HUELVA

Consejería de Turismo, Comercio y Deportes (2008): Guía de accesibilidad en comunicación para alojamientos turísticos en Andalucía. Empresa Pública Turismo Andaluz; en http://www.turismoandaluz.com/sites/accesibilidad/archivos/guia.pdf 
Consejería de Turismo, Comercio y Deportes (2010): Encuesta II Plan de Calidad Turística de Andalucía; en:

http://www.juntadeandalucia.es/turismocomercioydeporte/export/sites/ctcd/archivo s/prensa/Presentacixn_Plan_de_Calidad.pdf

Consejería de Turismo, Comercio y Deportes (2011): Turismo accesible. Dossier [Recurso electrónico]. Centro de Documentación y Publicaciones; en:http://www.juntadeandalucia.es/turismocomercioydeporte/documentacion/31604 .pdf

Consejería para la Igualdad y Servicios Sociales (2003): I Plan de Acción Integral para las Personas con Discapacidad en Andalucía 2003-2006. Junta de Andalucía; ver en: http://sid.usal.es/idocs/F8/FDO19001/plan_accion_ad.pdf

Consejería para la Igualdad y Servicios Sociales (2008): I Plan de Acción Integral para las Mujeres con Discapacidad en Andalucía (2008-2013). Junta de Andalucía; en http://www.juntadeandalucia.es/igualdadybienestarsocial/export/Personas_Discapaci dad/HTML/plan_mujer/index.html

Consejería para la Igualdad y Servicios Sociales (2011): II Plan de Acción Integral para las personas con discapacidad en Andalucía 2011-2013. Junta de Andalucía; en: http://www.juntadeandalucia.es/igualdadybienestarsocial/export/Personas_Discapaci dad/HTML/plan_accion_integral/Ilpaipda.html

Darcy, S. (1998): Anxiety to Access: Tourism Patterns and Experiences of New South Wales People with a physical Disability. Sydney, NSW: Tourism New South Wales.

Delgado, J. I. (2004): “Reflexiones sobre el Turismo Accesible”, en Turismo@Polibea, no 6, Real Patronato sobre Discapacidad, Ministerio de Trabajo y Asuntos Sociales.

Domínguez, T., Fraiz, J.A. y Alén, Mạ L. (2011): "La accesibilidad como oportunidad de mercado en el management de destinos turísticos", en VII Congreso Turismo y Tecnologías de la Información y las Comunicaciones Turitec, 2008; en:http://www.turismo.uma.es/turitec/turitec2008/paginas/articulos/actas_turitec_p df/L10_A09.pdf

Domínguez, T., Fraiz, J.A. y Alén, Ma L. (2011): “Turismo y accesibilidad. una visión global sobre la situación de España", en Cuadernos de Turismo, no 28, pp. 23-45. Univ. de Murcia; en: http://revistas.um.es/turismo/article/view/147151

Esteban Agueda, A. (2000): "La investigación turística en la Universidad Española", en Estudios Turísticos. № 144-145, pp. 155-180. Instituto de Estudios Turísticos. Secretaría General de Turismo; en: http://www.iet.tourspain.es/img-iet/Revistas/RET-144-1452000-pag155-180-84462.pdf

ISSN: 0212-8594 ISSN-e: 2340-2776.№ DOI: http://dx.doi.org/10.12795/rea.2014.i31.01 
EUROSTAT (1996): La discapacidad en cifras. Panel de Hogares de la Unión Europea; en http://usuarios.discapnet.es/AJimenez/Documentos/AJL/discapacidad-en-cifras.pdf

FEIJID (2011): Manual especializado de turismo accesible (META). Federación Provincial de Asociaciones de Personas con Discapacidad Física y Orgánica de Jaén; en http://jaenaccesible.org/turismoac/

FEJIDIF (2011): "Trato adecuado a las personas con discapacidad". Federación Provincial de Asociaciones de Personas con Discapacidad Física y Orgánica de Jaén, Inédito, 17 págs; en:

http://www.turismoaccesible.org/images/documentos/manuales/trato.doc

Fernández Alles, Mạ T. (2007): Turismo accesible: análisis de la accesibilidad hotelera en la provincia de Cádiz. Tesis Doctoral. Univ. de Cádiz, Inédito; en: http://minerva.uca.es/publicaciones/asp/docs/tesis/mtfernandezalles.pdf.

Fernández Alles, M.T. (2009): "Turismo accesible y turismo para todos en España: antecedentes, estado de la cuestión y futuras líneas de investigación", en Estudios Turísticos, no 180, pp. 141-153. Secretaría de Estado de Turismo, Madrid; en: http://www.iet.tourspain.es/img-iet/Revistas/RET-180-2009-pag141-153.pdf

Fernández Alles, M.T. (2009): "Turismo accesible: importancia de la accesibilidad para el sector turístico", en Entelequia, Revista interdisciplinar, no 9, pp. 2.014-2.015; en http://www.eumed.net/entelequia/.

Fernández Alles, M.T. (2011): "El análisis del entorno político y legal en el marco de la planificación estratégica en el sector turístico y hotelero", en Cuadernos de Gestión, Vol. 11, no 2, pp. 37-52. Univ. del País Vasco, Bilbao; en: http://www.ehu.es/cuadernosdegestion/documentos/100210mf.pdf

Fernández Tristancho, A. (2011): "Turismo accesible en Andalucía: un fin social necesario y rentable"; en JURADO ALMONTE, J.M. (Dir.): Recursos, potencialidades y modelos turísticos en Algarve, Baixo Alentejo y provincia de Huelva. Universidad de Huelva, pp. 357-372.

Franco, P. (1997): Manual de accesibilidad a hoteles para personas con movilidad reducida. Dirección General de Turismo y Real Patronato de Prevención y Atención a Personas con Minusvalía y Federación Española de Hoteles, Madrid.

Furnion, L. (2001): Le Tourisme des Personnes Handicapées: une adaptation nécessaire (Collection Jeunes auteurs ed.). Centre National de Ressources du Tourisme en Espace Rural, Lempdes.

ISSN: 0212-8594 ISSN-e: 2340-2776.N№ DOI: http://dx.doi.org/10.12795/rea.2014.i31.01 
Godoy, A., y Franco, P. (1999): Curso de Turismo Accesible. Real Patronato de Prevención y de Atención a Personas con Minusvalías. Madrid; en:

http://ibdigital.uib.es/greenstone/collect/portal_social/import/ministerio_trabajo_y_a suntos_sociales/discapacitats/monografia/200406220017_24_0.pdf

Grünewald, L.A. (1996): Calidad turística: pautas para un turismo accesible. Turismo para todos. Fundación Delia Lascano de Napp/Asociación Mutual Sociedad Central de Arquitectos, Argentina; en:

http://www.juntadeandalucia.es/igualdadybienestarsocial/opencms/system/modules/ com.opencms.presentacionCIBS/paginas/detalle.jsp?contenido=/Personas_Discapacid ad/Planes/II_PAIPDA

Huesca, Ana. M.; ORTEGA, E. (2005): Hábitos y actitudes hacia el turismo de las personas con discapacidad física. PREDIF, Madrid; en:

http://www.discapnet.es/Castellano/comunidad/websocial/Recursos/Documentos/Te cnica/Documents/a5f19dfbac1a42d4867dfa899bd45354guiapredifhabitosturismo.pdf

IECA (2009): Encuesta de Discapacidades, Autonomía Personal y situaciones de Dependencia EDAD 2008. Avance de resultados para Andalucía. Instituto de Estadística y Cartografía; en:

http://www.juntadeandalucia.es/institutodeestadisticaycartografia/dependencia/inde x.htm

IMSERSO (2002): Libro Verde. La accesibilidad en España. Diagnóstico y bases para un plan integral de supresión de barreras. Instituto Universitario de Estudios Europeos. Universidad Autónoma de Barcelona; en:

http://usuarios.discapnet.es/disweb2000/docu/LibroVerdeAccesibilidad.pdf

IMSERSO (2004): I Plan Nacional de Accesibilidad 2004-2012. Instituto de Mayores y Servicios Sociales (IMSERSO). Ministerio de Trabajo y Asuntos Sociales. 207 págs. Aprobado por el Consejo de Ministros de 25 de Julio de 2003; en: http://usuarios.discapnet.es/disweb2000/lex/AccePlan2004-2012.pdf

IMSERSO (2005): iPregúntame sobre accesibilidad y ayudas técnicas!, Instituto de Biomecánica de Valencia (IBV), Centro Estatal de Autonomía Personal y Ayudas Técnicas (CEAPTA) y Fundación ALIDES (Alianza para el Desarrollo Económico y Social). Madrid; en:

http://www.turismoaccesible.org/images/documentos/manuales/preguntamecomo.p df

INE (2011): Encuesta de Discapacidad, Autonomía personal y situaciones de Dependencia (EDAD-2008). Instituto Nacional de Estadística; en: http://www.ine.es/revistas/cifraine/1009.pdf

ISSN: 0212-8594 ISSN-e: 2340-2776.N№ DOI: http://dx.doi.org/10.12795/rea.2014.i31.01 
Jurado Almonte, J.M. (2014): "El turismo accesible en Andalucía y Portugal", en Cuadernos de Turismo, no 33, pp. 121-150, Universidad de Murcia. ISSN 1139-7861. Disponible on line en: http://revistas.um.es/turismo/article/view/195681/160201

Marcos Pérez, D. (2002): Manual de Accesibilidad Hotelera. Secretaría de Turismo. Secretaría de Estado de Comercio y Turismo. Ministerio de Economía; en: http://www.fundaciononce.es/libros/Turismo\%20para\%20todos\%20desde\%20la\%20a ccesibilidad\%20a\%20la\%20excelencia/Word\%20y\%20Pdf/Turismo\%20para\%20Todos\% 20desde\%20la\%20Accesibilidad\%20a\%20la\%20Excelencia_Parte\%20V.pdf

Marcos Pérez, D. y González Velasco, D. (2003): Turismo accesible: hacia un turismo de todos. CERMI, Mazars Turismo, Madrid; en: http://www.cermi.es/esES/ColeccionesCermi/Cermi.es/Lists/Coleccion/Attachments/51/4TurismoAccesible.pd $f$

Ministerio de Industria, Comercio y Turismo (2008): El mercado potencial del turismo accesible para el sector turístico español. Secretaría de Estado de Turismo; en: http://www.planaccesibilidadturistica.es/UserFiles/publicaciones/ficheros/Mercado_P otencial_Turismo_Accesible.pdf

Ministerio de Trabajo y Asuntos Sociales (2002): La discapacidad en cifras. DISCAPNET; en:

http://usuarios.discapnet.es/AJimenez/Documentos/AJL/discapacidad-en-cifras.pdf.

Molina Hoyo, M. y Cánoves Valiente, G. (2010): "Turismo accesible, turismo para todos: la situación en Cataluña y España", en Cuadernos de Turismo, no 25, pp. 25-44, Univ. de Murcia; en: http://revistas.um.es/turismo/issue/view/9441

Muñoz, María; Gómez; Javier; Arias, Fernando (2007): Catálogo de buenas prácticas en materia de accesibilidad en espacios naturales protegidos[Serie Manual 05-Manuales EUROPARC-España, Plan de acción para los espacios naturales protegidos del Estado español], Fundación Fernando González Bernáldez (ed.); en: http://www.jaenaccesible.org/documentacion/documentacion/Medio\%20ambiente/C atalogo\%20de\%20buenas\%20practicas\%20en\%20espacios\%20naturales.pdf

ONU (2006): Convención sobre los Derechos de las Personas con Discapacidad y ONU (2006): Protocolo Facultativo; en:

http://www.un.org/disabilities/documents/convention/convoptprot-s.pdf

PREDIF (2004): Hábitos y actitudes hacia el Turismo de las Personas con Discapacidad Física. Plataforma Representativa de Discapacitados Físicos, 103 págs.; en: http://www.predif.org/sites/default/files/documents/H\%C3\%A1bitos\%20y\%20Actitud es\%201\%C2\%AA\%20edc.pdf

ISSN: 0212-8594 ISSN-e: 2340-2776.№ DOI: http://dx.doi.org/10.12795/rea.2014.i31.01 
PREDIF (2009): Espacios y actividades en la naturaleza; accesibles para todas las personas", Plataforma Representativa de Discapacitados Físicos, 761 pág.; en: http://www.spain.info/turismo-accesible/guias/Guia_Parques_Naturales.pdf

PREDIF (2010): Guía de monumentos, museos y otros puntos de interés accesibles para todos. Plataforma Representativa de Discapacitados Físicos; Madrid, en: http://www.spain.info/turismo-accesible/guias/Monumentos_Museos_Accesibles.pdf

Real Patronato sobre Discapacidad (2007): Manual de Accesibilidad Universal para Hoteles. IMSERSO; en:

http://sid.usal.es/idocs/F8/FDO20170/manual_accesibilidad_hoteles.pdf

Rubio, A. (2000): "Paradojas en el paraíso: la accesibilidad de los servicios de naturaleza turística en España. Por un turismo de calidad y para todos", en Estudios Turísticos, Instituto de Estudios Turísticos. no 143, pp.13-40. Secretaría de Estado de Comercio y Turismo. Ministerio de Economía; Madrid, en: http://www.iet.tourspain.es/img-iet/Revistas/RET-143-2000-pag65-91-84422.pdf

Sala Mozos, E. y Alonso López, F. (2006): La accesibilidad universal en los municipios: guía para una política integral de promoción y gestión. Colección Manuales y Guías Serie Servicios Sociales, no 33003 IMSERSO; en: http://www.ceapat.es/InterPresent1/groups/imserso/documents/binario/accunivmun icipios.pdf

Sánchez, M. J.; Santiago, G., y Soret, P. (2007): Turismo para todos, desde la accesibilidad a la excelencia. Fundación ONCE. Madrid.

Sanchiz Pons, N. (1998): Turismo para Todos. Ceter CEE. Madrid.

Sanchiz Pons, N. (2000): Accesibilidad a Hoteles de 4 y 5 estrellas y Paradores Nacionales. Ceter CEE. Madrid.

Secretaría General de Turismo (2009): Decálogo de buenas prácticas en accesibilidad turística. Ministerio de Industria, Turismo y Comercio; en: http://www.planaccesibilidadturistica.es/publicaciones.php?id_actual=39

Soret Lafraya, P. (2005): "Turismo Accesible para todas las personas", en Actas del Congreso Nacional de Discapacidad "Accesibilidad Universal en el siglo XXI". Ponferrada, 30 de noviembre de 2005. 